\title{
Adherence to the CONSORT statement of randomized clinical trials on ART restorations in children: current status and reporting characteristics
}

Letícia Maria WAMBIER ${ }^{(a)}$

Angela da Ros GONÇALVES ${ }^{(b)}$ iD Denise Stadler WAMBIER ${ }^{(b)}$

Alessandra REIS ${ }^{(b)}$

Ana Cláudia Rodrigues

CHIBINSKI(b) iD

(a) Universidade Positivo, Department of Dentisty, Curitiba, PR, Brazil.

(b) Universidade Estadual de Ponta Grossa UEPG, Department of Dentistry, PR, Brazil.

Declaration of Interests: The authors certify that they have no commercial or associative interest that represents a conflict of interest in connection with the manuscript.

Corresponding Author:

Ana Cláudia Rodrigues Chibinski

E-mail: anachibinski@hotmail.com

https://doi.org/10.1590/1807-3107bor-2022.vol36.0017

Submitted: February 9,2021

Accepted for publication: August 3, 2021

Last revision: October 25, 2021
Abstract: Appropriate research reports are important to facilitate the evaluation of studies and the decision-making by dentists and policymakers. This meta-research study assessed the conformity of randomized clinical trials (RCTs) on atraumatic restorative treatment (ART) restorations with the CONSORT recommendations and their risk of bias (RoB). Cochrane Library, MEDLINE, BBO, LILACS, Scopus, and Web of Science databases were searched from April 2019 to June 2021 for RCTs that assessed the longevity of ART restorations in children. A specific tool was used to assess adherence to the CONSORT recommendations; RoB was evaluated with the Cochrane risk-of-bias tool. Descriptive analyses included the number of studies by journal, follow-up period, country, and quality assessments. A total of 2,181 papers were retrieved and 36 of them were analyzed qualitatively. The overall CONSORT mean score (CONms) was $22.52 \pm 6.17$ out of 32 points. The best described items were intervention and outcomes, whereas allocation concealment was described in only $22 \%$ of the papers. Significant differences in CONms were detected in the analysis by country and publication dates. High CONms were observed in recently published papers $(26.7 \pm 3.1)$ when compared to first ART studies $(18.1 \pm 4.6$; $\mathrm{p}<0.001)$. RoB was low in four studies, unclear in 11, and high in 21. Adherence of the papers to the CONSORT recommendations was not fully achieved and most of the papers had unclear and high RoB (PROSPERO registration \#CRD42020201460).

Keywords: Dental Atraumatic Restorative Treatment; Systematic Review; Randomized Controlled Trial.

\section{Introduction}

Atraumatic restorative treatment (ART) is a minimally invasive approach for the management of dental caries. Since its development in the mid-1980s and its endorsement by the World Health Organization (WHO) in 1994, the number of clinical trials on this technique has increased, assessing the longevity of ART restorations and their efficacy in controlling dental caries. 
ART, which began as an alternative for restoring teeth in underserved communities, has been currently used around the globe in public health dentistry as well as in private practices. This restorative approach is based on principles of minimally invasive dentistry, which recommends the preservation of the tooth structure, the maintenance of pulp vitality, and the prevention of pain and discomfort for the patient. ${ }^{1}$

To include the ART approach in their recommended protocols, clinicians and policymakers are greatly encouraged to make their treatment decisions based on the concepts of evidence-based dentistry (EBD). These concepts aim to increase the success of the intervention and to maximize its benefits to the patients. ${ }^{2}$

EBD is "grounded on a systematic process of establishing the level and the quality of the evidence" and the systematic reviews are the foundation of this process. ${ }^{3}$

Different systematic reviews about the ART protocol have been published. According to these reviews, ART can be successfully used for occlusal restorations in deciduous and permanent teeth ${ }^{4,5}$ and occlusal-proximal cavities may have a higher risk of failure. ${ }^{4,5}$ However, the statement that "new randomized clinical trials are needed to corroborate the findings" is common in systematic reviews, especially in those on occlusal-proximal cavities. ${ }^{6,7,8}$ Also, it is not uncommon to read that systematic reviewers were not able to find the information needed in a certain paper, ${ }^{7}$ which hampers the evaluation of potential bias.

One of the cornerstones of EBD is to minimize bias and provide reliable results. Systematic reviews and meta-analyses are based on primary studies to evaluate data qualitatively and quantitatively, aiming for the development of clinical practice guidelines. ${ }^{9}$ By combining primary studies, the final sample is enlarged, providing enhanced power to the results when compared to a single trial. However, the inclusion of papers irrespective of their veracity can originate misleading conclusions.

Publication of RCTs is as important as their accomplishment, with transparent and complete reporting so that readers can identify if the study has potential sources of systematic and random errors. To standardize the reporting of RCTs, in the early 1990s, a group of researchers and medical journal editors developed the CONSORT statement (Consolidated Standards of Reporting Trials). This statement was published in $1996^{10}$ and consists of a set of recommendations to improve the quality of RCT reports. The CONSORT statement provides the authors with a standardized and complete sequence of key components for reporting clinical trials, facilitating the reading and interpretation of the findings. Indirectly, the completeness of reporting could improve the methodological quality of RCTs.

Since the CONSORT statement was published, different dental journals have endorsed and recommended its use in RCTs. ${ }^{11}$ Nevertheless, it has been demonstrated that compliance with the CONSORT statement has not been fully adopted in different areas of dentistry, including implant dentistry, ${ }^{12}$ restorative dentistry, ${ }^{13-15}$ endodontics, ${ }^{16}$ orthodontics, ${ }^{17}$ and public health dentistry. ${ }^{18}$

In this way, it is important to identify possible flaws and improve practices associated with ART research to promote reproducibility and transparency in the research and in its reports. Meta-research is a tool that can be used to accomplish this goal. It is defined as the "study of the research itself"19 and it has five major areas of interest: methods, reporting, reproducibility, evaluation, and incentives. ${ }^{20} \mathrm{In}$ the present research, we focused our efforts on methods and reporting, i.e., on the identificationg of biases and questionable practices in conducting and communicating the ART research. To our knowledge, this is the first study to do that.

Therefore, the objective of this study was to perform a meta-research analyzing the compliance of RCTs on the longevity of atraumatic restorations in primary and permanent teeth with the CONSORT statement and the RoB of these studies according to the Cochrane tool for evaluation of RoB.

\section{Methodology}

\section{Protocol and registration}

This systematic review of the literature followed the recommendations of PRISMA 2020 for writing the research report ${ }^{21}$ and was carried out between April 
2019 and June 2021 at the State University of Ponta Grossa, Paraná, Brazil. This study was registered with PROSPERO (CRD42020201460).

\section{Sources of information and search strategy}

The eligible studies were searched in different electronic databases, namely Cochrane Library, MEDLINE via PubMed, Brazilian Library in Dentistry (BBO), and Latin American and Caribbean Literature in Health Sciences (LILACS). Citation databases such as Scopus and Web of Science were also searched. Reference lists for all primary studies were also manually searched. Gray literature was not consulted because this research evaluated the quality of studies published in indexed peer-reviewed journals and we did not aim to estimate the efficacy of the ART protocol.

The search strategy was assembled initially for MEDLINE via PubMed. For this purpose, the terminology for indexing biomedical information (MeSH terms) and free terms presented in titles and abstracts were combined using the Boolean operator "OR" within concepts of the search strategy and the Boolean operator "AND" for different concepts. Subsequently, the search strategy was adapted for other databases (Figure 1).

\section{Eligibility criteria}

Randomized clinical trials that evaluated the longevity of ART restorations on children's deciduous and permanent teeth were included. Considering the date of the first publication of the CONSORT statement, we only included studies published from 1996 to 2021. Reports published in any media other than peer-reviewed journals were excluded. No language restriction was applied.

\section{Selection of studies and data collection process}

The papers were selected by title and abstracts; duplicates were considered once. If the title and abstract did not provide enough information to make a clear decision, full-text articles were obtained. Subsequently, two reviewers (A.D.R.G. and L.M.W.) classified those articles that met the inclusion criteria. Data were extracted using customized forms including information about the name of the journal, year of publication, country of the main author, study design, follow-up period of the trial, and number of patients/teeth, among other information. When multiple papers from the same research were found (reports with different follow-up periods), the data were extracted from the newest report; if information about CONSORT adherence was still missing, the previous reports from the same research could be searched for the lacking information; in this case, the set of papers was considered to be one entry.

\section{Compliance with the consort statement}

Compliance with the CONSORT statement was evaluated through a previously tested instrument applied to other studies (Table 1). ${ }^{14,15}$ The CONSORT assessment tool is based on the items "material and methods" and "results" from the CONSORT Declaration of 2010.22

The tool includes a total of 12 criteria from the CONSORT statement. Given that some of them have subdivisions, a total of 16 items were assessed. Each item received a score from 0 to 2 (score $0=$ no description, score 1 = poor description; score $2=$ adequate description). Before paper evaluation, the instrument was revised and all items were discussed between two authors (A.C.R.C and L.M.W). Both authors then evaluated the included studies with the CONSORT tool. In case of a discrepancy in the scoring process for any item, a third author was contacted (D.S.W.).

Evaluators were not blinded to authorship of the paper. This was not possible because they were familiar with the theme and publications; also, the research center could be easily discovered after article reading.

\section{Risk of bias in individual studies}

Risk of bias assessment was performed by two independent reviewers (A.D.R.G and L.M.W), using the Cochrane Collaboration's tool version 1.0.23 The RoB tool contains six domains: sequence generation, allocation concealment, blinding of patients/masking of evaluators, incomplete outcome data, selective outcomes reporting, and other possible sources of bias.

The judgment of each entry involved 'yes', indicating low risk of bias; 'no', indicating high risk of bias; and 


\section{Pubmed $=903(17 / 02 / 2020)$}

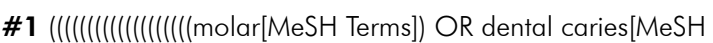

Terms]) OR tooth, deciduous[MeSH Terms]) OR dentition, permanent[MeSH Terms]) OR dentition, mixed[MeSH Terms]) OR molar[Title/Abstract]) OR "dental caries"[Title/Abstract]) OR "tooth deciduous"[Title/Abstract]) OR "dentition permanent"[Title/Abstract]) OR "dentition mixed"[Title/Abstract]) OR "occlusal surfaces"[Title/Abstract]) OR "posterior teeth"[Title/Abstract]) OR "posterior tooth"[Title/Abstract]) OR "Class II"[Title/Abstract]) OR "Class I"[Title/Abstract]) OR "Class 2"[Title/Abstract]) OR "Class 1"[Title/Abstract])))

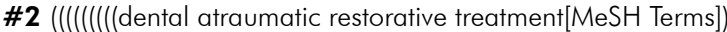
OR "dental atraumatic restorative treatment"[Title/Abstract]) OR "atraumatic restorative treatment" [Title/Abstract]) OR ART[Title/Abstract]) OR IRT[Title/Abstract]) OR "minimal intervention"[Title/Abstract]) OR "partial caries removal"[Title/Abstract]) OR "ART restorations"[Title/Abstract]))

\section{\# 1 AND \#2}

\section{Scopus $=571(17 / 02 / 2020)$}

\# 1 ( TITLE-ABS-KEY ( molar) OR TITLE-ABS-KEY ( "dental caries" ) OR TITLE-ABS-KEY ( "t?? ?th deciduous") OR TITLE-ABS-KEY ( "dentition permanent" ) OR TITLE-ABS-KEY ( "dentition mixed") OR TITLE-ABS-KEY ( "occlusal surfaces" ) OR TITLE-ABS-KEY ( "posterior t??+h" ) OR TITLE-ABS-KEY ( "class II") OR TITLE-ABS-KEY ( "class I" ) OR TITLE-ABS-KEY ( "class 7") OR TITLE-ABS-KEY ( "class 2" ) )
\#2 ( TITLE-ABS-KEY ( "dental atraumatic restorative

treatment" ) OR TITLE-ABS-KEY ( "atraumatic restorative treatment") OR TITLE-ABS-KEY ( art) OR TITLE-ABS-KEY ( int OR TITLE-ABS-KEY ( "minimal intervention") OR TITLE-ABS-KEY ( "partial caries removal") OR TITLE-ABS-KEY ( "ART restorations" ) ) ) AND ( LIMIT-TO ( SUBJAREA, "DENT" ) )

\section{\#1 AND 2 AND \#3}

Web of Science- $393(17 / 02 / 2020)$

\# 1 TOPIC: (molar) ORTOPIC: ("dental caries") ORTOPIC: (" $+*$ th deciduous") ORTOPIC: ("dentition permanent") ORTOPIC: ("dentition mixed") ORTOPIC: ("occlusal surfaces") ORTOPIC: ("posterior $\left.t^{*}+h^{\prime \prime}\right)$ ORTOPIC: ("class I") ORTOPIC: ("class II") ORTOPIC: ("class 1") ORTOPIC: ("class 2")
TOPIC: ("dental atraumatic restorative treatment") ORTOPIC: ("atraumatic restorative treatment") ORTOPIC: (ART) ORTOPIC: (IRT) ORTOPIC: ("minimal intervention") ORTOPIC: ("partial caries removal") ORTOPIC: ("ART restorations") AND ( DENTISTRY ORAL SURGERY MEDICINE )

\section{\#1 AND \#2}

\section{Lilacs and $\mathrm{BBO}=41(17 / 02 / 2020)$}

\# 1 (mh:(molar)) OR (mh:(dental caries)) OR (mh:(tooth, deciduous)) OR (mh:(dentition, permanent)) OR (mh:(dentition, mixed)) OR (tw:("occlusal surfaces")) OR (tw:("posterior teeth")) OR $(\mathrm{tw}:($ "posterior tooth")) OR (tw: ("class II")) OR (tw:("class I")) OR $($ tw: ("class 2")) OR (tw:("class1")) OR (tw:("superfíciesoclusais")) OR (tw:("dentesposteriores")) OR (tw:("dente posterior")) OR (tw:("classe II")) OR (tw:(“classe I")) OR (tw:(“classe 1")) OR (tw:(“classe 2")) OR (tw: ("superficies oclusales")) OR (tw: ("dientesposteriores")) OR $($ tw: ("diente posterior")) OR (tw: ("clase II")) OR (tw:("clase I")) OR $(\mathrm{tw}:($ "clase 2")) OR (tw:("clase 1"))
\#2 (mh:(dental atraumaticrestorativetreatment)) OR (tw: ("atr aumaticrestorativetreatment")) OR (tw: (ART)) OR (tw:(IRT)) OR (tw: ("minimalintervention")) OR (tw:("partial caries removal")) OR (tw: ("ART restorations")) OR (tw: ("tratamiento de restauración atraumático")) OR (łw:("intervención mínima")) OR (†w: ("extirpación parcial de caries")) OR (tw:("restauraciónes ART")) OR (tw:("restauraciónes TRA")) OR (tw:(TRA)) OR (tw:("tratamento restaurador atraumático")) OR (†w:("mínima intervenção")) OR (tw:("remoção parcial de cárie")) OR (tw:("restaurações ART"))

\section{\#1 AND \#2 AND \#3}

\section{Cochrane Library $=259(17 / 02 / 2020)$}

\# 1 MeSH descriptor: [Molar] explode all trees

\#2 MeSH descriptor: [Dental caries] explode all trees

\#3 MeSH descriptor: [Tooth, deciduous] explode all trees

\#4 MeSH descriptor: [Dentition, permanent] explode all trees

\#5 MeSH descriptor: [Dentition, mixed] explode all trees

\#6 molar:ti,ab,kw or "dental caries":ti,ab, kw or

t*thdeciduous:ti,ab, kw or "dentition permanent":ti,ab, kw or "dentition mixed": ti,ab,kw(Word variations have been searched)

\#7 "occlusal surface":ti,ab,kw or posterior $+^{*}+h: t i, a b, k w$ or "class

II": $: \mathrm{i}, \mathrm{ab}, \mathrm{kw}$ or "class I": ti, ab, kw(Word variations have been searched) \#8 "class 1":ti,ab,kw(Word variations have been searched)

\#9 \# 1 OR \#2 OR \#3 OR \#4 OR \#5 OR \#6 OR \#7 OR \#8
\#1 MeSH descriptor: [Molar] explode all trees

\#2 MeSH descriptor: [Dental caries] explode all trees \#3 MeSH descriptor: [Tooth, deciduous] explode all trees \#4 MeSH descriptor: [Dentition, permanent] explode all trees \#5 MeSH descriptor: [Dentition, mixed] explode all trees \#3 \# 1 OR \#2

\#4"Atraumatic restorative treatment":ti,ab, kw orART:ti,ab, kw or ART near technique*:ti,ab,kw orART near restoration*:ti,ab, kw or ART near sealant*:ti,ab,kw(Word variations have been searched) \#5IRT:ti,ab,kw or "interim restorative technique":ti,ab, kw or "ART approach":ti,ab,kw or "dental restoration":ti,ab,kw or "minimal intervention":ti,ab, kw(Word variations have been searched) \#6 ionomer:ti,ab,kw or "partial caries removal":ti,ab,kw(Word variations have been searched)

\#7 \#3 OR \#4 OR \#5 OR \#6

\#9 AND \#7 AND \#6

Figure 1. Search strategy in the different databases (February 17, 2020). 
Table 1. Evaluation tool for assessment of adherence of studies to CONSORT recommendations. ${ }^{14,15}$

\begin{tabular}{|c|c|c|c|}
\hline \multirow{2}{*}{$\begin{array}{l}\text { CONSORT } \\
\text { item }\end{array}$} & \multirow{2}{*}{ Sub item } & \multirow{2}{*}{ Score } & Adherence of methods and results items to the CONSORT statement \\
\hline & & & Description \\
\hline \multirow{4}{*}{ Study design } & & Positive [2] & The drawing of the essay is clearly written in the text (split mouth, parallel, factorial, cluster). \\
\hline & & Negative [0] & This information is not reported. \\
\hline & & & $\begin{array}{l}\text { 1. Information can be obtained during the reading of the manuscript, although this is not } \\
\text { explicitly reported by the authors. }\end{array}$ \\
\hline & & Poor [1] & $\begin{array}{l}\text { 2. There is a lack of consistency between the sections of the article (examples - the abstract } \\
\text { does not correspond to the material and methods section; the presentation of the results } \\
\text { does not correspond to the description of the study design; the flowchart presents different } \\
\text { information, etc.). }\end{array}$ \\
\hline \multirow{8}{*}{ Participants } & \multirow{5}{*}{$\begin{array}{l}\text { Eligibility } \\
\text { criteria }\end{array}$} & Positive [2] & $\begin{array}{l}\text { The inclusion and exclusion criteria are clear, so readers can know exactly know which } \\
\text { population the data can be extrapolated to. }\end{array}$ \\
\hline & & Negative [0] & This information is not reported. \\
\hline & & & 1. Incomplete information oneligibility criteria compared to most field studies. \\
\hline & & Poor [1] & $\begin{array}{l}\text { 2. Presence of inconsistencies in the inclusion/exclusion criteria that prevent readers from } \\
\text { knowing the population in which the intervention/control groups were performed. }\end{array}$ \\
\hline & & Positive [2] & $\begin{array}{l}\text { Clear description of the scenario (academic, practice-based research, university, private } \\
\text { clinics, etc.), as well as the date on which the intervention was implemented. }\end{array}$ \\
\hline & \multirow{3}{*}{$\begin{array}{l}\text { Search field } \\
\text { and location }\end{array}$} & Negative [0] & The setting and/or location are not reported in the text. \\
\hline & & Porr $[1]$ & 1. The authors describe the scenario or date, but never both. \\
\hline & & roor [1] & 2. This information can be obtained indirectly in the text. \\
\hline \multirow{3}{*}{ Interventions } & & Positive [2] & $\begin{array}{l}\text { The interventions for each group are described in sufficient detail to allow replication, } \\
\text { including how they were actually administered. }\end{array}$ \\
\hline & & Negative [0] & No description. \\
\hline & & Poor [1] & Missing information that prevents replication of interventions/comparators. \\
\hline \multirow{3}{*}{ Outcomes } & & Positive [2] & $\begin{array}{l}\text { At least the primary results were defined in detail, including how and when they were } \\
\text { evaluated. Consider this to be clear when the details are clear, but the authors did not use } \\
\text { the term "primary result" or related synonyms. }\end{array}$ \\
\hline & & Negative [0] & There is no definition of primary outcome and/or secondary outcomes. \\
\hline & & Poor [1] & $\begin{array}{l}\text { The authors only report having used specific criteria without providing details about the most } \\
\text { important results of these criteria. }\end{array}$ \\
\hline \multirow[t]{3}{*}{ Sample Size } & & Positive [2] & $\begin{array}{l}\text { The sample size calculation method is described, allowing replication. The primary result for } \\
\text { each calculated sample size should be identified. The elements of sample size calculation } \\
\text { are ( } 1 \text { ) the estimated results in each group (implying the clinically important target difference } \\
\text { between the intervention groups); (2) the error level } \alpha \text { (type I); (3) statistical power (or } \beta \text { error } \\
\text { level (type II)); and (4), for continuous results, the standard deviation of the measurements } \\
\text { should be reported. For equivalence runs, the equivalence limit instead of the size of the } \\
\text { effect size should be reported. }\end{array}$ \\
\hline & & Negative [0] & There is no description in the article. \\
\hline & & Poor [1] & The sample size is described, but some parameters are missing, avoiding replication. \\
\hline \multirow{7}{*}{ Randomization } & \multirow{4}{*}{$\begin{array}{l}\text { Sequence } \\
\text { generation }\end{array}$} & Positive [2] & 1. Clear description of random sequence generation. \\
\hline & & rositive [L] & 2. Or clear description of a non-random sequence method. \\
\hline & & Negative [0] & There is no information in the text. \\
\hline & & Poor [1] & $\begin{array}{l}\text { The authors only provide a very superficial description (such as the "groups were } \\
\text { randomly allocated") or do not provide enough information to allow replication of the } \\
\text { randomization process. }\end{array}$ \\
\hline & \multirow{3}{*}{$\begin{array}{c}\text { Allocation } \\
\text { concealment }\end{array}$} & Positive [2] & Clear description of allocation concealment. See the next columns for risk of bias assessment. \\
\hline & & Negative [0] & There is no information in the text. \\
\hline & & Poor [1] & Not applicable. \\
\hline
\end{tabular}




\begin{tabular}{|c|c|c|c|}
\hline \multirow{2}{*}{$\begin{array}{l}\text { CONSORT } \\
\text { item }\end{array}$} & \multirow{2}{*}{ Sub item } & \multirow{2}{*}{ Score } & Adherence of methods and results items to the CONSORT statement \\
\hline & & & Description \\
\hline \multirow{3}{*}{ Blinding } & & Positive [2] & $\begin{array}{l}\text { 1) The authors describe who is blinded to the study.2. In blinded studies (when this is clearly } \\
\text { reported by the authors), the description of the participant or evaluator (the blinded one) is } \\
\text { sufficient; However, when the study is double-blind or triple-blind, all blinded people should } \\
\text { be described. 2) The study describes only the participant or blinded examiner, but one of } \\
\text { these people cannot be blinded by resources intrinsic to the study design. }\end{array}$ \\
\hline & & Negative [0] & There is no description of blinding. \\
\hline & & Poor [1] & $\begin{array}{l}\text { Poor/partial information. For example, (1) the authors describe the blinding of examiners or } \\
\text { the blinding of participants, but never both. (2) The authors describe the study as blind or } \\
\text { double-blind, but do not specify who was blinded. }\end{array}$ \\
\hline \multirow{6}{*}{$\begin{array}{l}\text { Statistical } \\
\text { methods }\end{array}$} & \multirow{3}{*}{$\begin{array}{l}\text { Hypothesis } \\
\text { testing }\end{array}$} & Positive [2] & $\begin{array}{l}\text { Statistical methods are described in sufficient detail, allowing a knowledgeable reader to } \\
\text { have access to the original data and verify the reported results. In addition, the statistical tests } \\
\text { employed by the authors seem to be appropriate for the type of study and the nature of the } \\
\text { data collected. }\end{array}$ \\
\hline & & Negative [0] & Statistical methods are not described. \\
\hline & & Poor [1] & $\begin{array}{l}\text { There is insufficient information to evaluate the statistical method used by the author and/or } \\
\text { the type of statistical tests employed by the authors are inappropriate for the design and/or } \\
\text { nature of the data (e.g., tests that do not take into account the paired nature of the data } \\
\text { when this is the case). 2) The authors describe several statistical tests, but do not specify to } \\
\text { which outcome they were applied. }\end{array}$ \\
\hline & \multirow{3}{*}{$\begin{array}{l}\text { Effect size } \\
\text { estimation }\end{array}$} & Positive [2] & $\begin{array}{l}\text { The authors report, at least for the primary result, the size of the effect and its accuracy (as a } \\
95 \% \text { confidence interval). Odds ratio, risk ratio, risk difference, mean difference, etc. }\end{array}$ \\
\hline & & Negative [0] & No description of effect size and confidence interval. \\
\hline & & Poor [1] & Incomplete information. \\
\hline \multirow{7}{*}{$\begin{array}{l}\text { Flow of } \\
\text { participants }\end{array}$} & \multirow{4}{*}{ Flowchart } & Positive [2] & $\begin{array}{l}\text { For each group, the number of participants who were randomly assigned, received the } \\
\text { desired treatment, and were analyzed for the primary result is described in the flowchart. }\end{array}$ \\
\hline & & Negative [0] & The flowchart is not presented in the article. \\
\hline & & Poor [1] & $\begin{array}{l}\text { 1.There are inconsistencies between the numbers described in the flowchart and other parts } \\
\text { of the manuscript. }\end{array}$ \\
\hline & & & 2. Incomplete diagram with missing information. \\
\hline & \multirow{3}{*}{$\begin{array}{l}\text { Losses/ } \\
\text { Exclusions }\end{array}$} & Positive [2] & $\begin{array}{l}\text { 1. For each group, losses and exclusions after randomization and their reasons are described. } \\
\text { 2.During the reading, the reviewer notes that there are no losses in the follow-up period. }\end{array}$ \\
\hline & & Negative [0] & No description of losses or exclusions. \\
\hline & & Poor [1] & $\begin{array}{l}\text { Incomplete information. For example, } 1 \text {. The authors describe the overall percentage of } \\
\text { losses, but this information is not specified by group. } 2 \text {. The authors describe the losses and } \\
\text { exclusions, but do not specify the reasons. }\end{array}$ \\
\hline \multirow{5}{*}{ Baseline data } & & Positive [2] & $\begin{array}{l}\text { A description of the table/text containing the demographic and clinical characteristics of the } \\
\text { baseline of each group is presented in the article. }\end{array}$ \\
\hline & & Negative [0] & There is no table/text description with baseline or description data in the body of the text. \\
\hline & & \multirow{3}{*}{ Poor [1] } & $\begin{array}{l}\text { 1. A table/description of text with baseline data is displayed, but the data are not distributed } \\
\text { between the study groups and/or data as percentages instead of raw numbers. }\end{array}$ \\
\hline & & & 2. Poor information about the participants. \\
\hline & & & 3. Inconsistencies may be observed in the data. \\
\hline \multirow{6}{*}{\multicolumn{2}{|c|}{ Numbers analyzed }} & Positive [2] & $\begin{array}{l}\text { For each group and for each result, the number or participants (denominator) included in the } \\
\text { analysis is clear. }\end{array}$ \\
\hline & & Negative [0] & The authors do not report the numbers analyzed. \\
\hline & & \multirow{4}{*}{ Poor [1] } & $\begin{array}{l}\text { 1. There is no clear description of the number of participants (denominator) included in the } \\
\text { analysis of at least one of the results. }\end{array}$ \\
\hline & & & 2. Instead of reporting the raw number of participants, the authors report their data as percentages. \\
\hline & & & 3. The authors do not report the baseline number of patients included in each analysis. \\
\hline & & & 4. Data can be obtained indirectly in the study. \\
\hline
\end{tabular}




\begin{tabular}{lll}
$\begin{array}{lll}\text { Continuation } \\
\text { CONSORT } \\
\text { item }\end{array}$ & Sub item & Adherence of methods and results items to the CONSORT statement \\
\cline { 3 - 3 } & Positive [2] & $\begin{array}{l}\text { The study was recorded in a test record and the protocol number is provided. } \\
\text { Registration and Protocol }\end{array}$ \\
Pegative [0] & $\begin{array}{l}\text { This information is not available in the manuscript. Registration with the Ethics Committee is } \\
\text { not valid as a study record. }\end{array}$ & $\begin{array}{l}\text { The authors describe that the study was registered, but did not provide the registration } \\
\text { number and/or the registration number is not linked to the study. }\end{array}$ \\
\hline
\end{tabular}

'unclear', indicating lack of information or uncertainty about the potential bias. During the quality assessment of individual studies, any differences between reviewers were solved through discussion and, when necessary, by consulting a third reviewer (A.C.R.C.).

The studies were considered to have a "low" risk of bias if all the domains showed a low risk. If one or more criteria showed a high risk of bias, the study was considered to have a "high" risk of bias. The study was judged as "unclear" when one or more domains had an unclear risk of bias.

\section{Scoring system and statistical analysis}

Data on the included papers were assigned to four categories: journal of publication, year of publication, follow-up periods, and country of the first author, including descriptive data and mean scores obtained with the CONSORT tool.

After the normality test (Shapiro-Wilk), the comparison within each factor for the CONSORT scores was performed by ANOVA with Tukey's post-hoc test (95\% confidence intervall; and significance level of 0.05) (SigmaPlot, Systat Software Inc., Germany).

Correlation analysis was performed between the CONSORT mean score and: a) the 2020 ISI impact factor of the journal in which the paper was published; b) the risk of bias of the paper; c) year of publication (Spearman's linear correlation). Correlation analysis was also used to assess the impact factor of the journal with the Cochrane RoB toolscore (Friedman linear correlation) (Medcalc, Medcalc Software Ltd, Belgium).

\section{Results}

\section{Characteristics of the included studies}

Initially, a total of 2,181 studies were retrieved. After removing the duplicates, 1,256 papers remained.
The reading of titles and abstracts lowered this number to 50 articles. From these, 14 were excluded for the following reasons: a) three studies were study protocols, ${ }^{24,25,26}$ b) four studies were only about ART sealants; ${ }^{27,28,29,30} \mathrm{c}$ ) two studies did not evaluate the longevity of ART restorations; ${ }^{31,32} \mathrm{~d}$ ) one study was a review of another paper; ${ }^{33}$ e) two studies included adult patients; ${ }^{34,35}$ and f) two studies associated ART with other techniques in the same research $\operatorname{arm}^{36,37}$ (Figure 2). Therefore, the study included 36 papers.

Included RCTs investigated different follow-up periods (from 6 months to 6 years); in most studies, the follow-up period ranged from 0 to 24 months (63.9\%). Most of the included RCTs were published in the following journals: Clinical Oral Investigations (16.7\%), Caries Research (11.1\%), International Journal of Paedriatric Dentistry (11.1\%), and Community Dentistry Oral Epidemiology (8.3\%). The other papers (52.8\%) came from 16 different journals (Table 2).

Brazil accounted for more than one-third of the publications worldwide (41.7\%); other countries were China (13.9\%), the Netherlands (8.3\%), and Turkey $(8.3 \%)$. The remaining papers were from India, Kenya, Tanzania, South Africa, Kuwait, Syria, and Australia, which together represented $27.8 \%$ of the publications (Table 2).

The periods with the largest number of published articles were from 1999 to 2004 (33.3\%) and 2015 to 2021 (38.9\%). The 2005-2009 and 2010-2014periods encompassed $27.8 \%$ of the publications (Table 2).

Most of the studies exhibited a parallel or split-mouth design. Glass ionomer cement was usually compared with composite resin, stainless steel crowns (Hall technique), different brands of glass ionomer cements (including resin-modified GIC and low-cost GICs), and amalgam. The number of restorations in the studies varied from 59 to 1,891, 


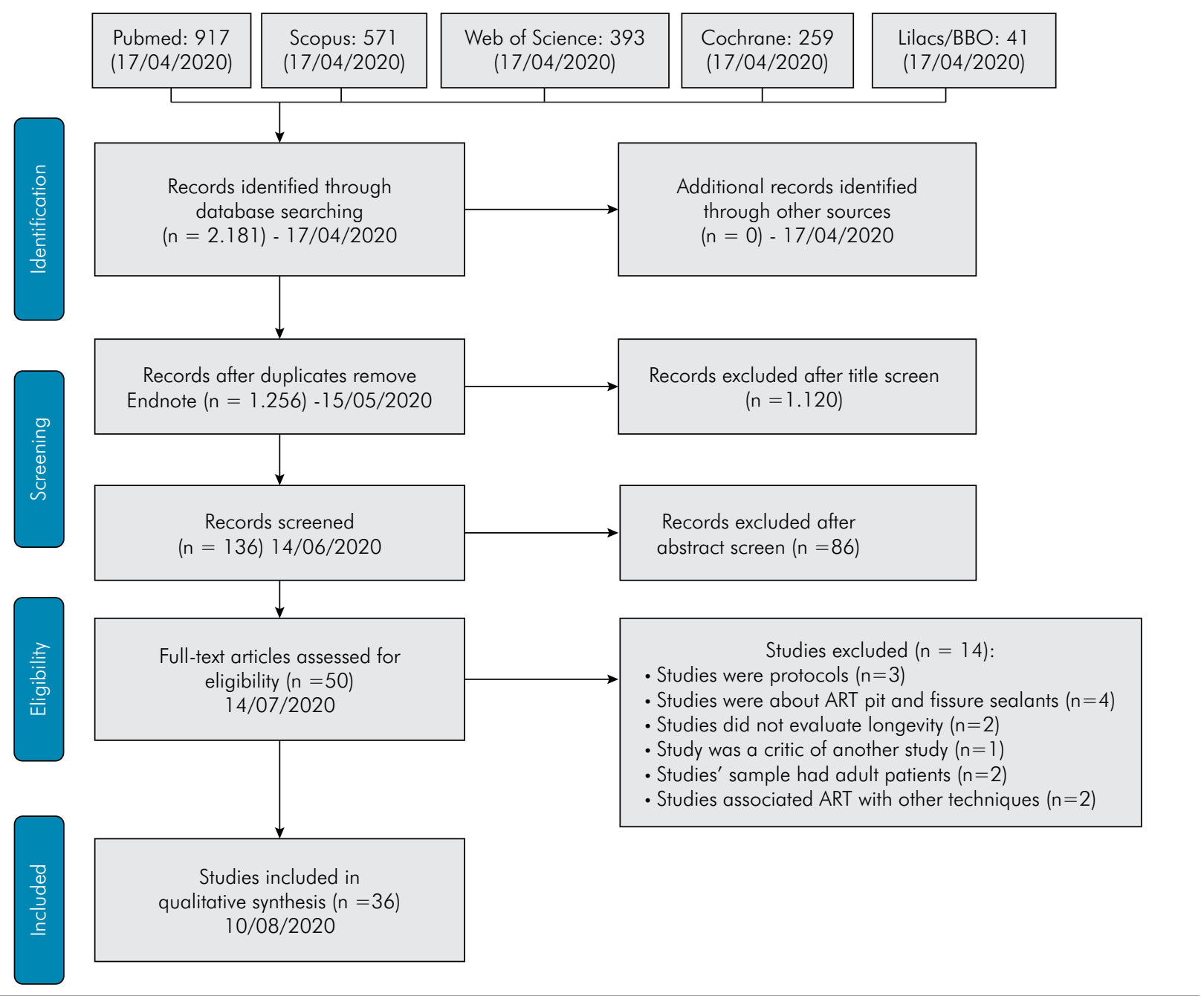

Figure 2. Flowchart of the search strategy steps in databases.

and most of them were performed on primary teeth. Both occlusal and occlusal-proximal restorations were performed in 16 studies; only occlusal restorations were included in 10 studies; only occlusal-proximal restorations were performed in nine studies; and occlusal, occlusal-proximal cavities and class III restorations were tested in one study (Table 3 ).

\section{Compliance with the consort tools}

Figure 3 shows the percentage of compliance of included studies with each item of the CONSORT evaluation tool. The best described items were intervention and outcomes, which were appropriately reported by all included papers, followed by hypothesis testing, effect size, and numbers analyzed, which were well described by more than $70 \%$ of the included studies. Criteria such as eligibility, blinding of participants or evaluators, and losses/exclusion were described by approximately $60 \%$ of the papers. Allocation concealment was described by only $22.2 \%$ of the papers; protocol registration was present in $36.1 \%$ of the papers and flowchart in $41.7 \%$.

\section{Consort mean scores according to study characteristics}

The overall score for CONSORT items in the studies included in this review was $22.52 \pm 6.17$, which represents $70.37 \%$ of the maximum CONSORT score (32 points). There are significant differences in the CONSORT mean scores of the studies when the data were analyzed by country and publication dates (Table 4). 
Table 2. Characteristics of the included studies by category.

\begin{tabular}{|c|c|c|}
\hline Category & Number of studies & Percentage \\
\hline \multicolumn{3}{|l|}{ Journal } \\
\hline Clinical Oral Investigation & 6 & 16.7 \\
\hline Caries Research & 4 & 11.1 \\
\hline Int. Journal of Paedriatric Dentistry & 4 & 11.1 \\
\hline Community Dent. Oral Epidemiol. & 3 & 8.3 \\
\hline Other* & 19 & 52.8 \\
\hline \multicolumn{3}{|l|}{ Countries } \\
\hline Brazil & 15 & 41.7 \\
\hline China & 5 & 13.9 \\
\hline Netherlands & 3 & 8.3 \\
\hline Turkey & 3 & 8.3 \\
\hline Other ** & 10 & 27.8 \\
\hline \multicolumn{3}{|l|}{ Time period } \\
\hline $1999-2004$ & 12 & 33.3 \\
\hline $2005-2009$ & 4 & 11.1 \\
\hline $2010-2014$ & 6 & 16.7 \\
\hline $2015-2021$ & 14 & 38.9 \\
\hline \multicolumn{3}{|l|}{ Follow-up time (year) } \\
\hline 0 to 12 months & 12 & 33.3 \\
\hline 13 to 24 months & 11 & 30.6 \\
\hline 25 to 36 months & 8 & 22.2 \\
\hline 37 to 48 months & 3 & 8.3 \\
\hline more than 48 months & 2 & 5.6 \\
\hline
\end{tabular}

*Other: 16 journals (BMC Oral Health; Brazilian Dental Science, Pediatric Dentistry, Journal of the Indian Society of Pedodontics and Preventive Dentistry, Journal of Applied Oral Science, Journal of Public Health Dentistry, Contemporary Clinical Dentistry, Journal of Dentistry for Children, Journal of the South African Dental Association, Brazilian Oral Research, Journal the American Dental Association, International Dental Journal, Medical Principles and Practice, Nigerian Journal of Clinical Practice, Journal of Clinical Paediatric Dentistry, Quintessence International, and Journal of Dentistry); ${ }^{* *}$ Other: 7 countries (Kenya, Tanzania, South Africa, Australia, Kuwait, India, and Syria)

Regarding the journals, no significant differences were detected between the CONSORT mean scores when different journals were analyzed (Table 4). Clinical Oral Investigations presented the best scores with a total of 6 papers $(27.5 \pm 3.4)$, followed by Caries Research (four papers; $22.5 \pm 3.9$ ) and International Journal of Paediatric Dentistry (four papers; $21.5 \pm 3.9$ ).

When the country of the first author was considered, a significant difference was observed $(p<0.001$; Table 4). Brazil had the highest number of papers and the highest CONSORT mean score (26.8 \pm 3.2$)$, which was statistically different from China, Turkey, and other countries, except for the Netherlands, which received the second-best CONSORT mean score. Besides Brazil and the Netherlands (21.6 \pm 4.5$)$, the highest mean scores were achieved by a group of papers from different countries such as India, Kuwait, Kenya, Syria, Tanzania, South Africa, and Australia (20.8 \pm 4.5$)$.

An increase in the CONSORT mean scores was observed in more recently published papers (2015-2021) (26.7 \pm 3.1$)$ when compared to first ART studies conducted from 1999 to 2004 (18.1 $\pm 4.6 ; \mathrm{p}=0.001)$ (Table 4).

When analyzing the follow-up period of the restorations, no differences were observed in the CONSORT mean scores ( $p=0.274$; Table 4$)$. The follow-up periods varied between studies; most of the included studies had a follow-up period between 0 and 24 months (Table 2).

\section{Risk of BIAS of the included studies}

Only four studies included in the review were considered to have a lowRoB; ${ }^{38-41} 11$ papers were judged to have an unclear risk, ${ }^{42-52}$ and 21 had a high RoB $^{25,53-67}$ (Figure 4).

Adequate random sequence generation and allocation concealment were achieved by $47 \%$ and $25 \%$ of the studies, respectively. Blinding of the examiners was more common than blinding of the participants. Selective reporting was the only domain in which all the studies presented a "low RoB" with an appropriate description (Figure 5).

\section{Correlation between variables}

Weak and non-significant correlations were found between the CONSORT mean scores and the journal's impact factor $[\mathrm{r}=-0.03(95 \% \mathrm{CI}-0.35-0.30) ; \mathrm{p}=0.87]$; the RoB in the studies and the impact factor of the journals in which they were published $[\mathrm{r}=-0.19$ (95\%CI $-0.49-0.15)$; $\mathrm{p}=0.26)$, and the RoB scores in the studies and the CONSORT scores $[\mathrm{r}=-0.03$ (95\%CI $-0.35-0.30)$; $\mathrm{p}=0.88]$. The only strong correlation was found between CONSORT mean scores and publication year [r=0.67 (95\%CI 0.46-0.82) $\mathrm{p}<0.0001]$.

\section{Discussion}

In the dental literature and in the biomedical literature in general, it is not uncommon to detect failures, both in designing and reporting clinical trials ${ }^{68}$. 


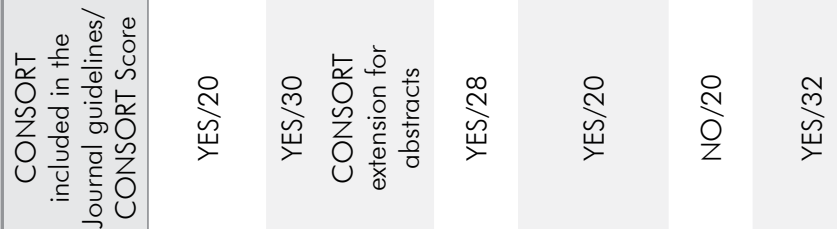

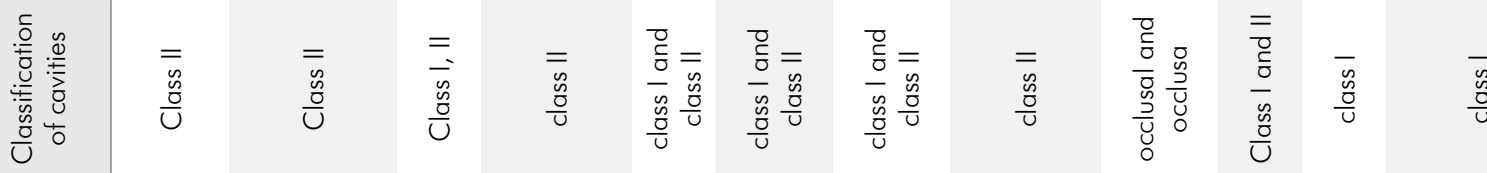

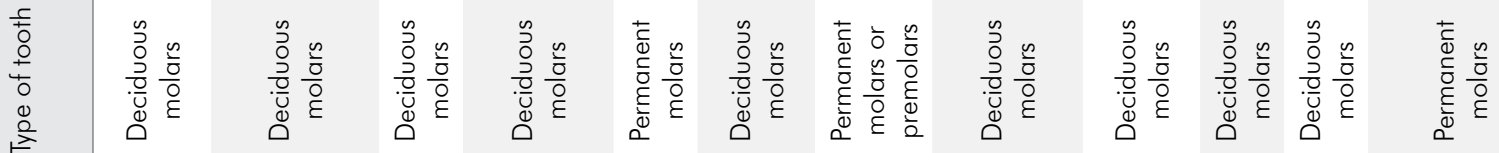

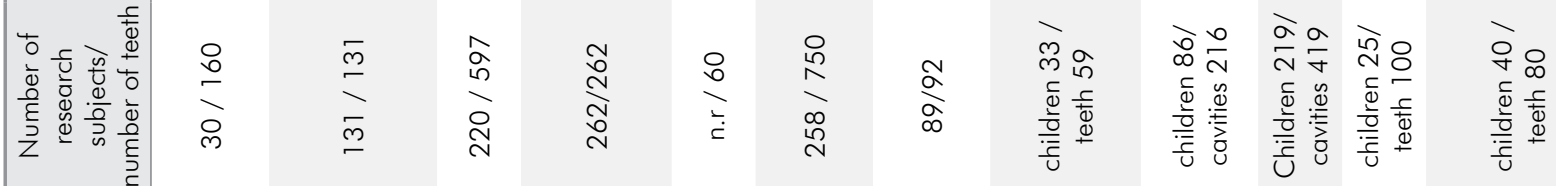

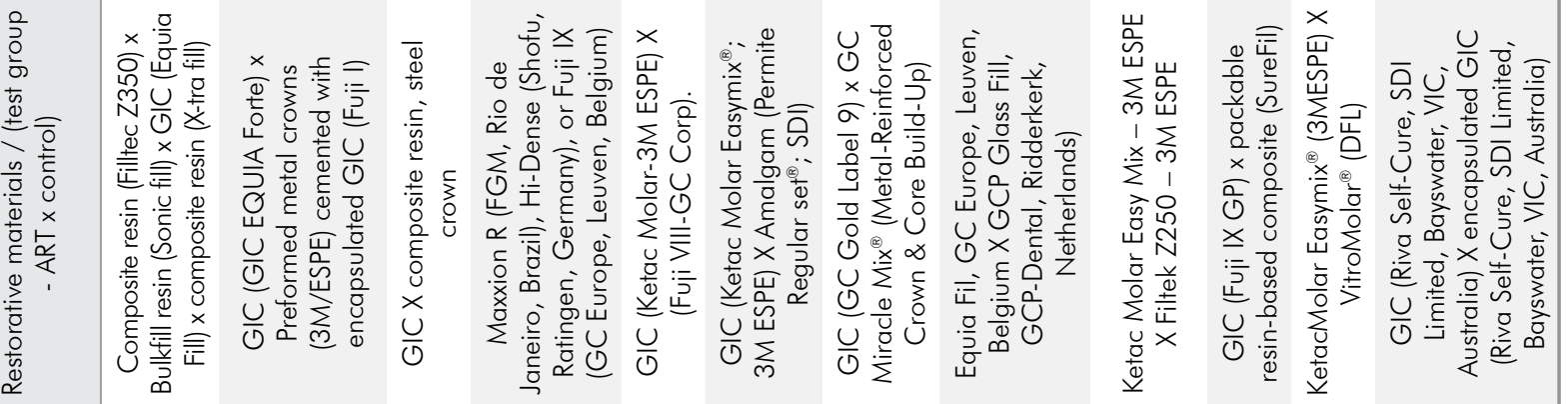

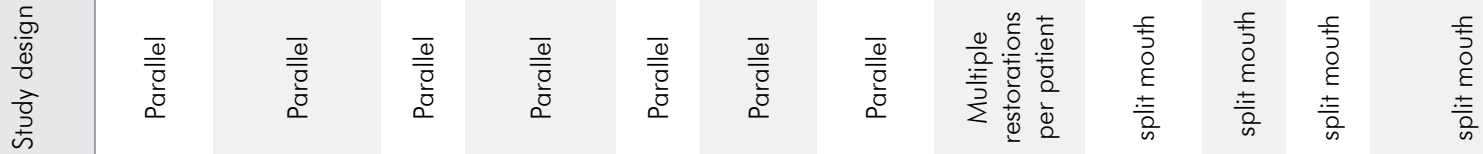

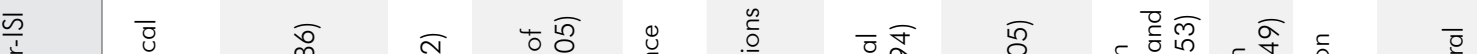

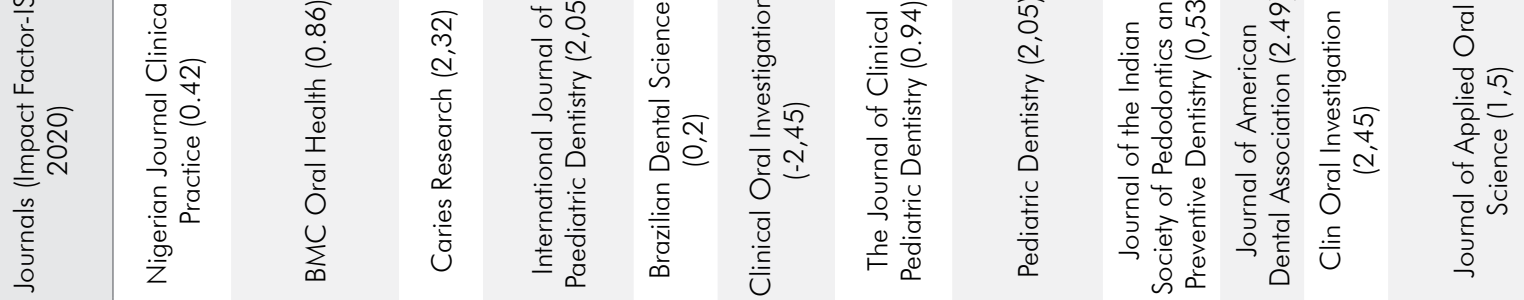

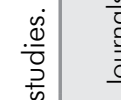

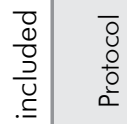

$-\frac{.0}{\underline{0}}$

$\underline{0}$

$\stackrel{\dot{c}}{\check{2}} \quad \succ$

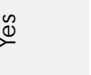

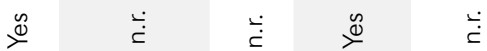

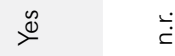

$\stackrel{\mathscr{g}}{2}$

$\stackrel{\mathscr{b}}{\longleftarrow}$

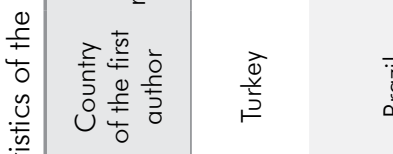

产

竞

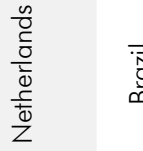

$\sqrt{\overline{5}}$

$\overline{\overline{0}}$

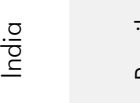

$\begin{array}{lllll}\overline{\bar{N}} & \overline{\bar{N}} & \overline{\bar{D}} & \overline{\bar{N}} & \overline{\bar{N}} \\ \bar{D} & \bar{D} & \frac{\bar{N}}{\bar{D}} & \bar{D}\end{array}$

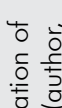

牙

总:

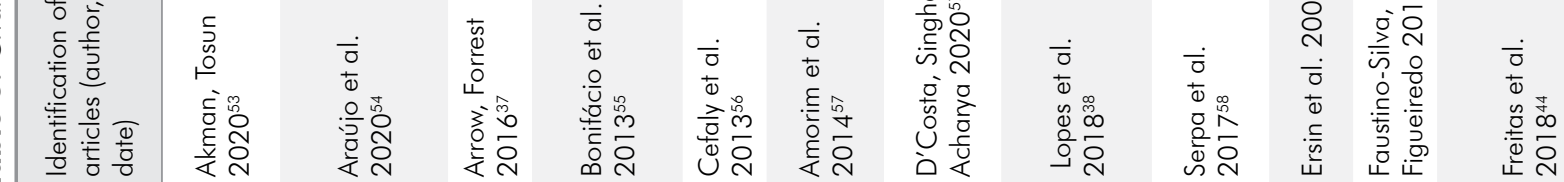

s.

产

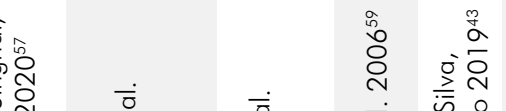




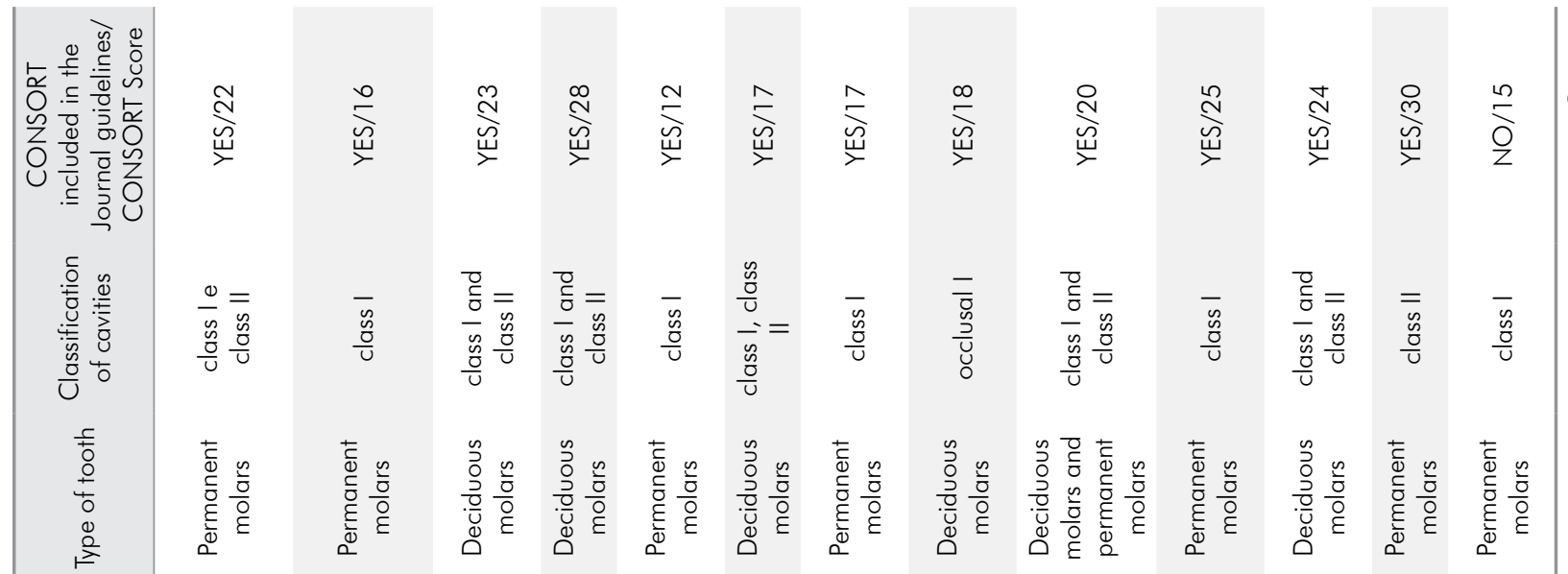

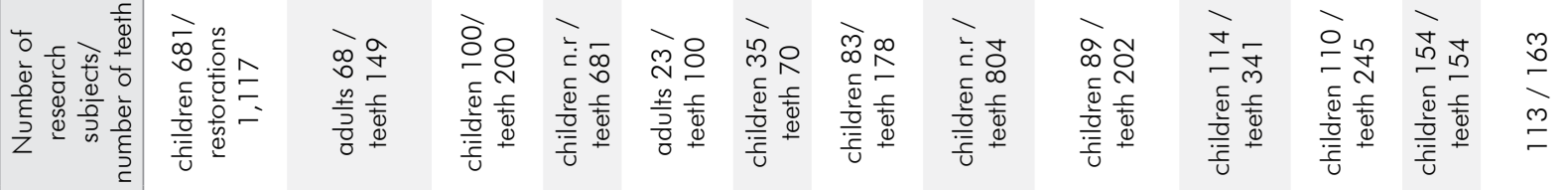

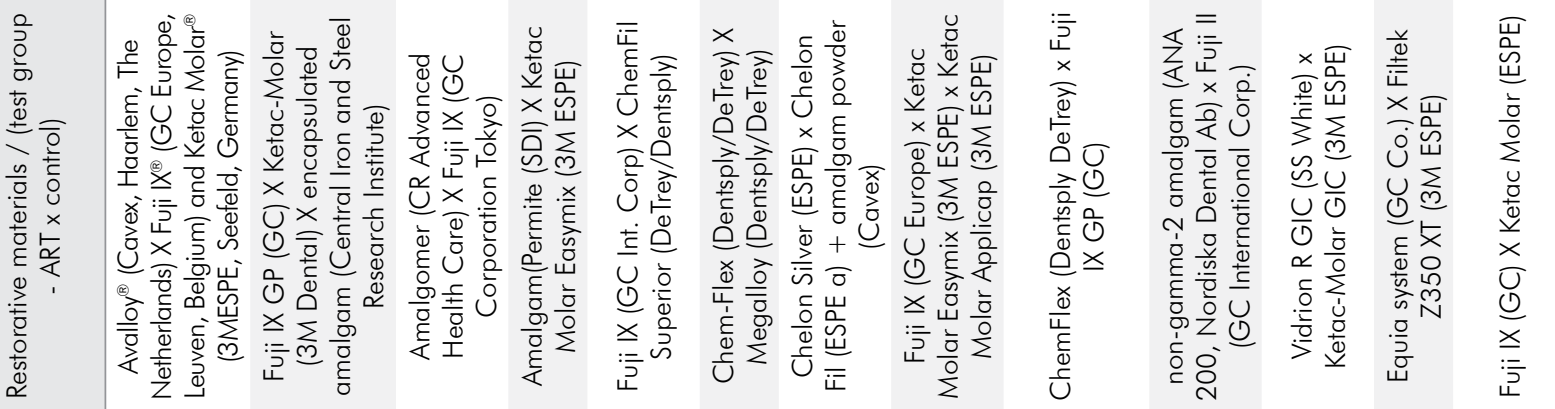

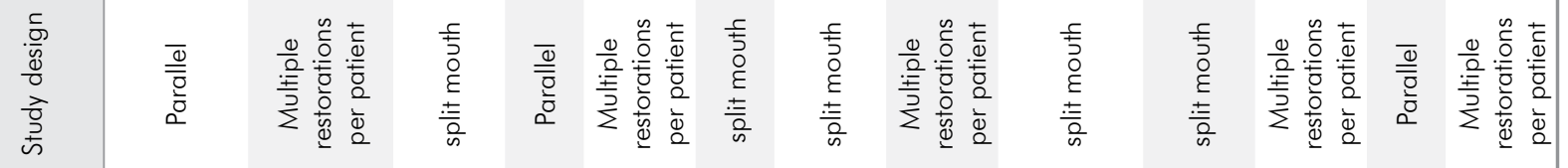

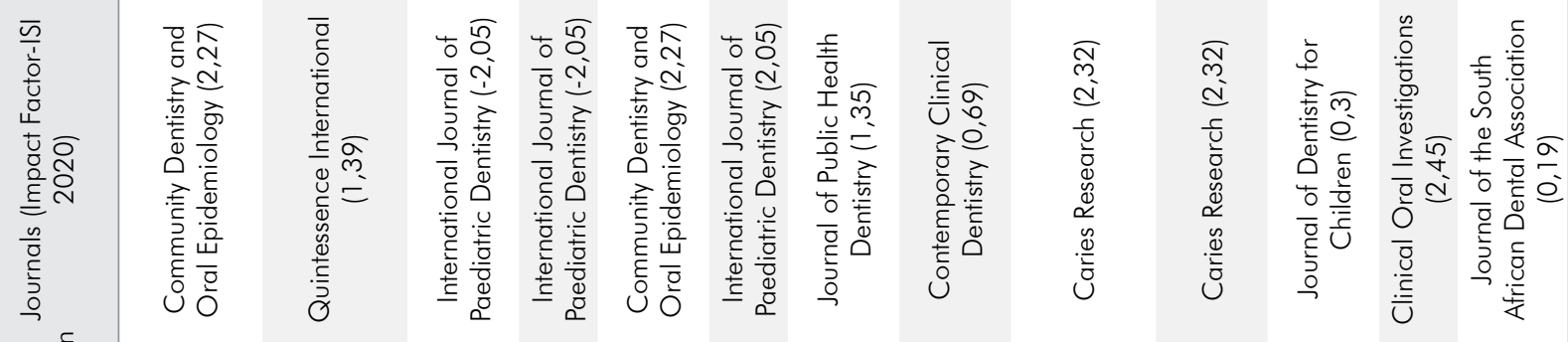

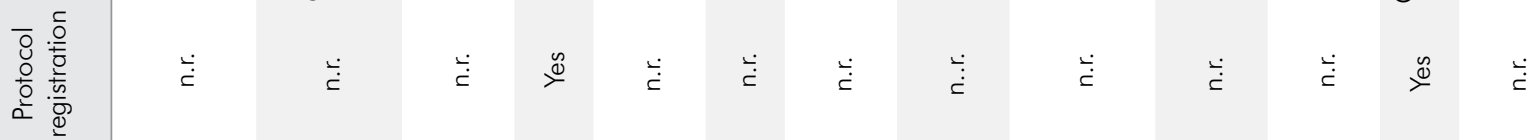

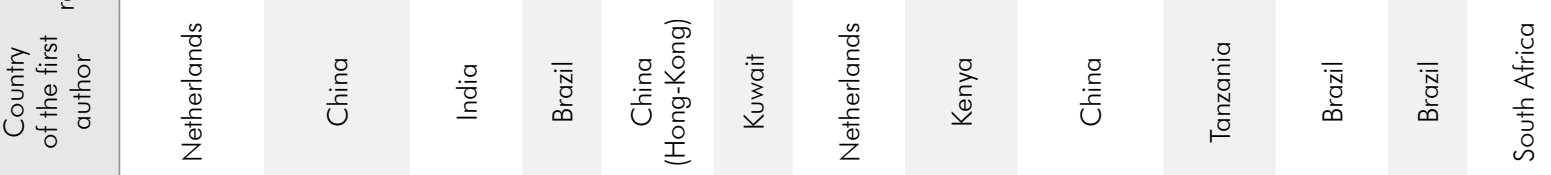

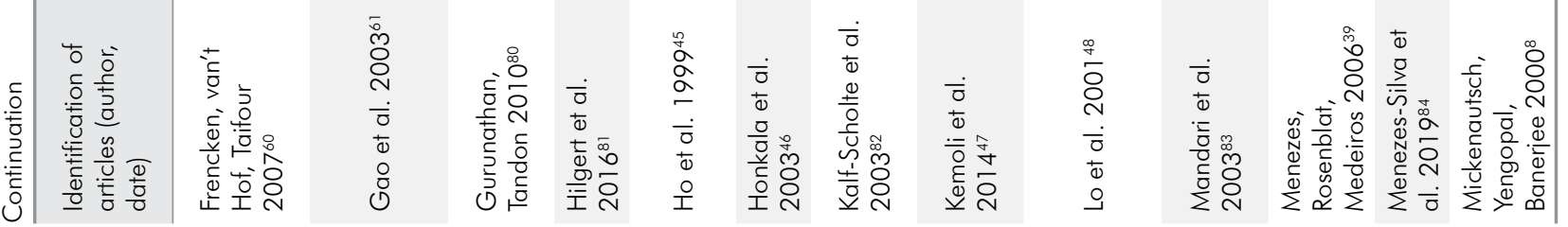




\begin{tabular}{|c|c|c|c|c|c|c|c|c|c|c|c|}
\hline 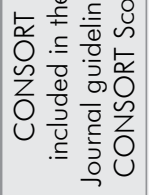 & 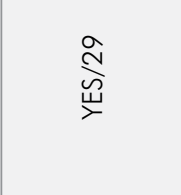 & 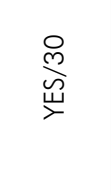 & 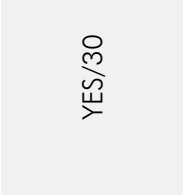 & 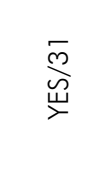 & 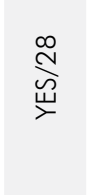 & $\underset{\underset{\nu}{\breve{~}}}{\stackrel{\infty}{亠}}$ & 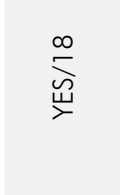 & $\underset{\underset{\nu}{\stackrel{N}{~}}}{\bar{\sim}}$ & $\underset{\stackrel{\varpi}{\varpi}}{\stackrel{\sim}{\longleftarrow}}$ & 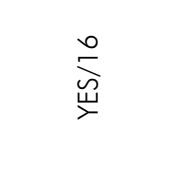 & 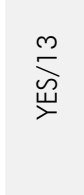 \\
\hline 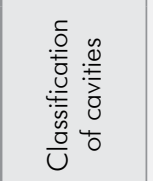 & 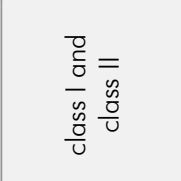 & 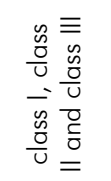 & 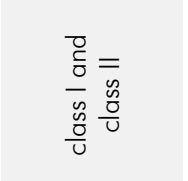 & $\begin{array}{l}\overline{\bar{n}} \\
\bar{O} \\
\bar{U}\end{array}$ & $\begin{array}{l}= \\
\overline{\mathscr{D}} \\
\frac{\tilde{U}}{U}\end{array}$ & 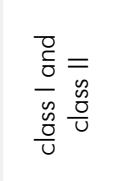 & 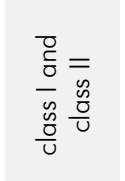 & $\begin{array}{l}\overline{=} \\
\underline{\tilde{O}} \\
\underline{U}\end{array}$ & $\begin{array}{l}\overline{\tilde{n}} \\
\overline{\tilde{O}} \\
\bar{v}\end{array}$ & 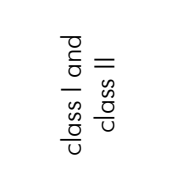 & $\begin{array}{l}\overline{\tilde{O}} \\
\overline{\tilde{O}}\end{array}$ \\
\hline $\begin{array}{l}\frac{1}{5} \\
\overline{0} \\
\frac{0}{4} \\
\frac{0}{0} \\
\mathbb{0} \\
\stackrel{0}{\geq}\end{array}$ & 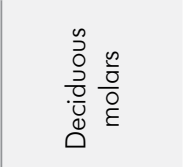 & 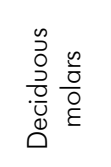 & 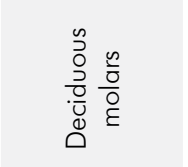 & 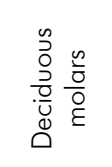 & 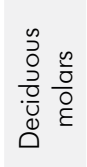 & 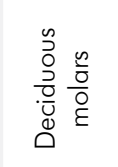 & 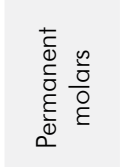 & 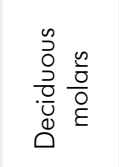 & 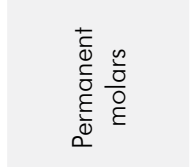 & 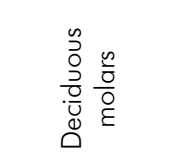 & 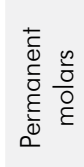 \\
\hline 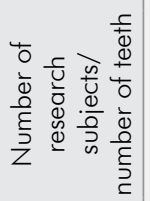 & 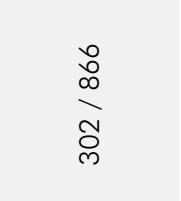 & $\frac{\stackrel{\infty}{N}}{\stackrel{m}{m}}$ & $\begin{array}{l}\infty \\
i \\
i \\
i \\
i n\end{array}$ & 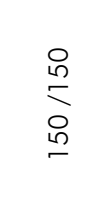 & $\begin{array}{l}£ \\
\equiv \\
\equiv\end{array}$ & 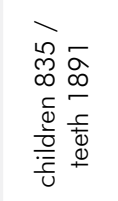 & 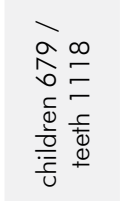 & 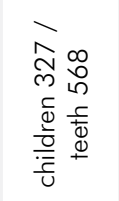 & 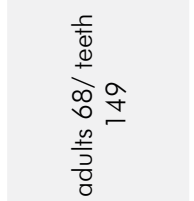 & 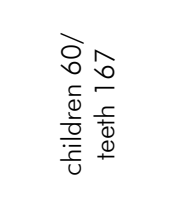 & 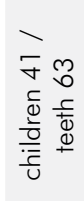 \\
\hline 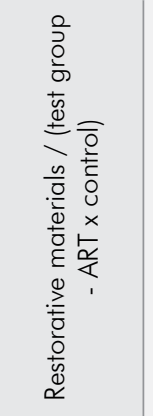 & 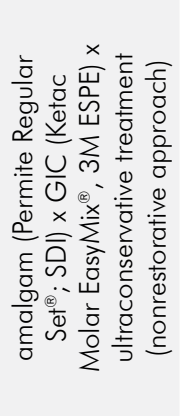 & 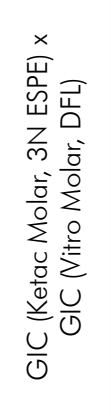 & 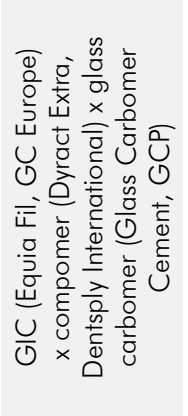 & 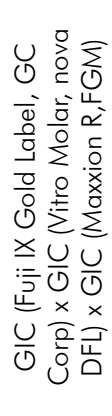 & 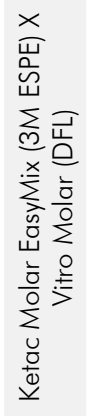 & 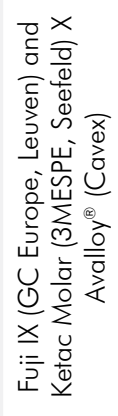 & 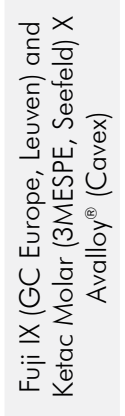 & 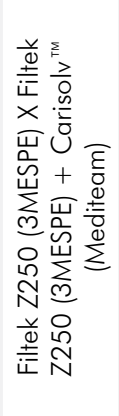 & 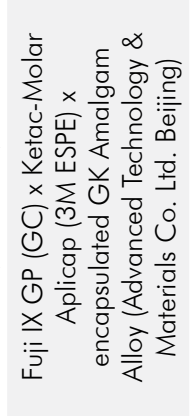 & 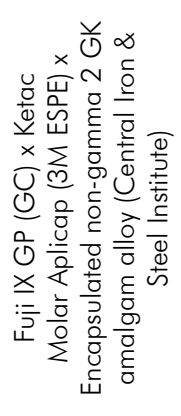 & 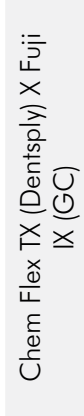 \\
\hline $\begin{array}{l}\frac{5}{0} \\
\frac{0}{0} \\
0 \\
\frac{0}{0} \\
\dot{0}\end{array}$ & $\begin{array}{l}\overline{\overline{0}} \\
\overline{\overline{\overline{0}}} \\
\overline{0}\end{array}$ & 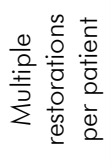 & 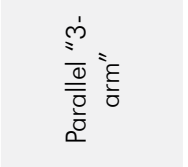 & 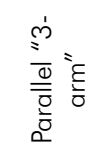 & $\begin{array}{l}\overline{\bar{\Phi}} \\
\overline{\overline{\bar{D}}} \\
\Delta \bar{U}\end{array}$ & $\begin{array}{l}\bar{\Phi} \\
\overline{\overline{\bar{\sigma}}} \\
\overline{0}\end{array}$ & $\begin{array}{l}\frac{\bar{\Phi}}{\overline{\bar{D}}} \\
\overline{\overline{0}}\end{array}$ & $\frac{\bar{\Phi}}{\overline{\overline{\bar{\sigma}}}}$ & 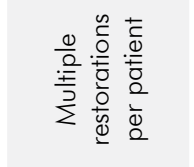 & 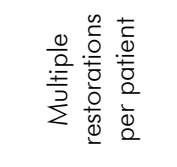 & $\grave{c}$ \\
\hline 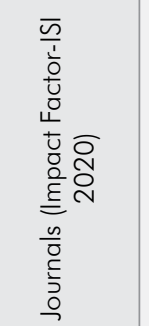 & 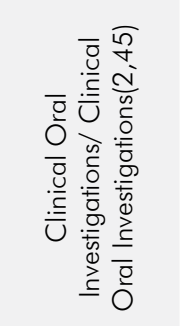 & 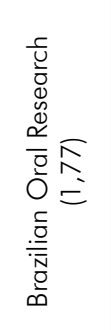 & 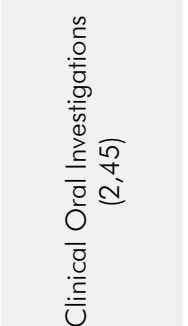 & 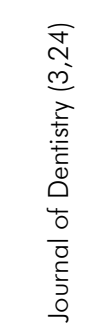 & 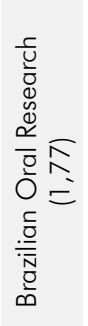 & 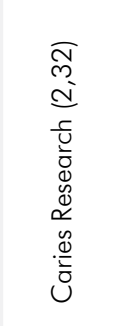 & 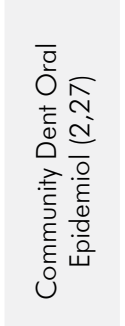 & 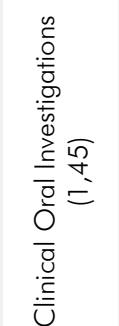 & 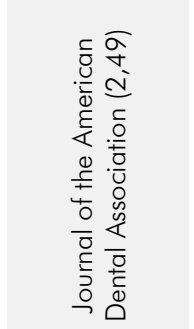 & 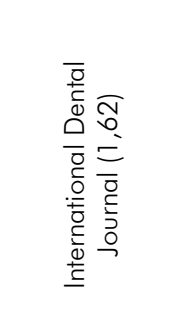 & 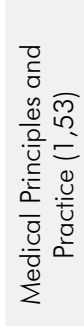 \\
\hline 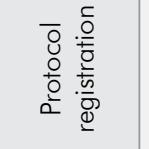 & 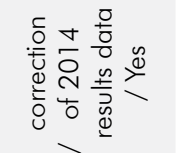 & $\stackrel{\mathscr{0}}{\varnothing}$ & $\stackrel{\mathscr{b}}{\check{D}}$ & $\stackrel{\infty}{\stackrel{\infty}{\infty}}$ & $\stackrel{\varpi}{\rightleftharpoons}$ & $\stackrel{\stackrel{\check{C}}{c}}{ }$ & $\ddot{\check{c}}$ & $\stackrel{\check{C}}{\dot{C}}$ & $\stackrel{\leftrightarrow}{\stackrel{\rightleftarrows}{c}}$ & $\stackrel{\ddot{\check{E}}}{ }$ & 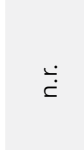 \\
\hline 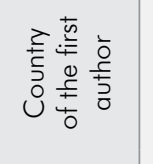 & 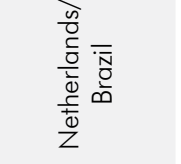 & 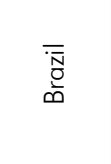 & $\begin{array}{l}\overline{\bar{N}} \\
\bar{D}\end{array}$ & $\begin{array}{l}\overline{\bar{N}} \\
\stackrel{\bar{D}}{D}\end{array}$ & $\overline{\overline{\bar{O}}}$ & $\frac{0}{2}$ & 旁 & $\begin{array}{l}\text { बे } \\
\stackrel{\vec{\nu}}{5}\end{array}$ & 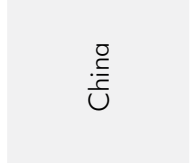 & 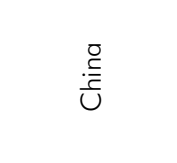 & $\begin{array}{l}\text { 䓂 } \\
\text { 章 } \\
\underline{y}\end{array}$ \\
\hline 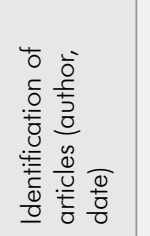 & 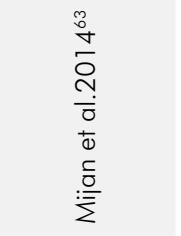 & 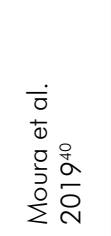 & 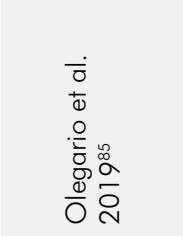 & 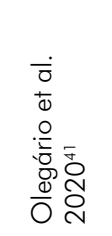 & 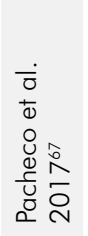 & 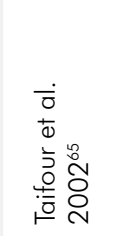 & 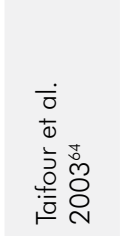 & 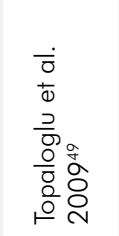 & 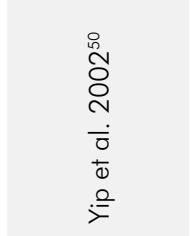 & 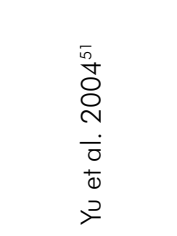 & 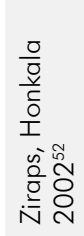 \\
\hline
\end{tabular}




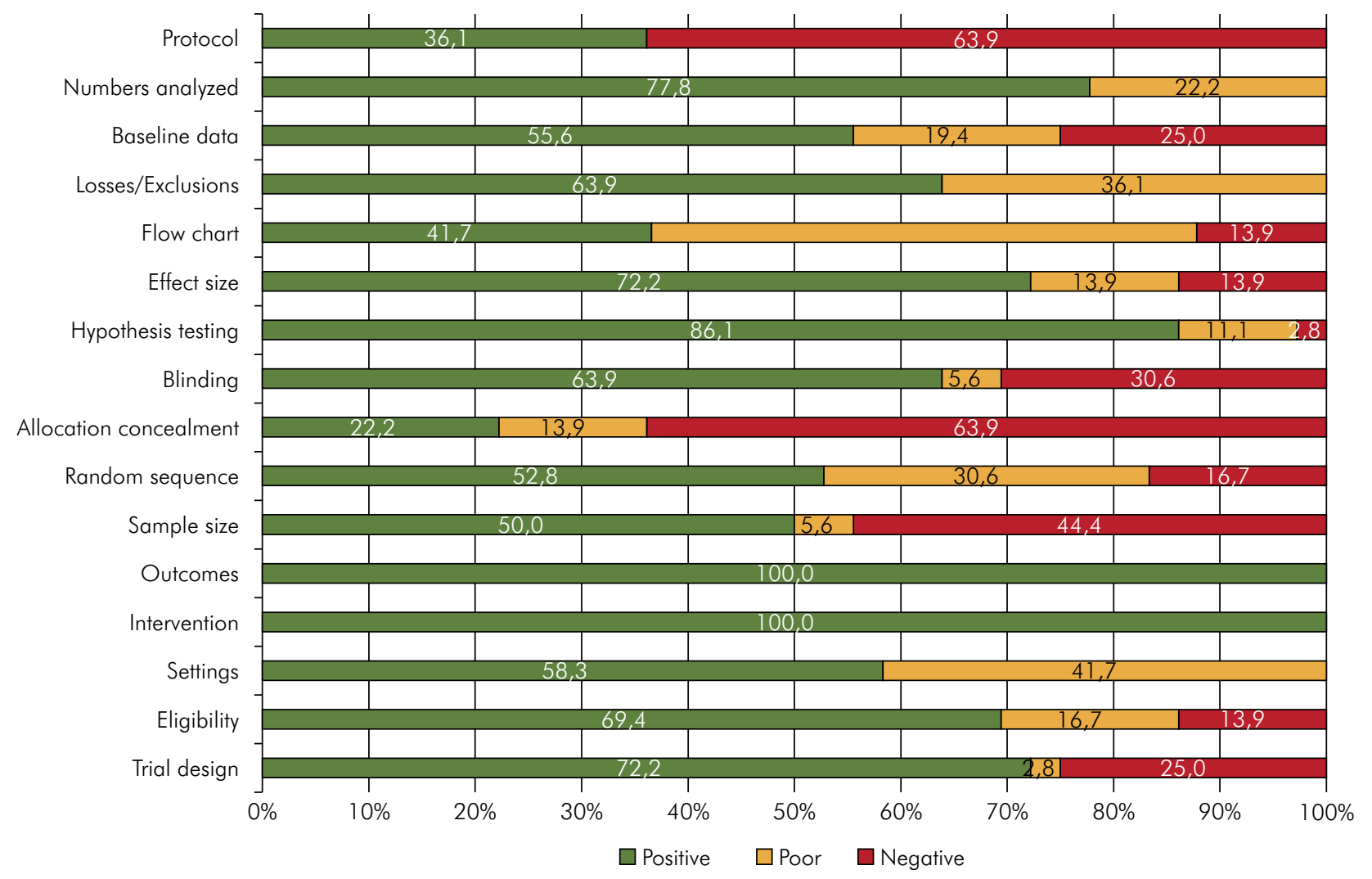

Figure 3. Percentage of studies according to CONSORT scores for each analyzed criterion.

With the increasing number of journals that encourage authors to follow CONSORT recommendations, research reports would be expected to present clearer and more complete information. ${ }^{69}$ In our study, the mean CONSORT score was $22.52 \pm 6.17$, which represents moderate compliance with CONSORT recommendations $(70 \%$ of the maximum CONSORT score -32 points).

The CONSORT recommendations are not an instrument to assess the quality of RCTs, ${ }^{69}$ but a guide to help authors write research reports. The quality of RCTs can be assessed with the Cochrane ROB tool. In this meta-research, we combined both tools, focusing on items related to the description of the methodology and research results.

Our results showed THAT the largest number of papers focused on the longevity of ART restorations WERE published in four journals. Among the other 16 journals with publications on this topic, only three did not recommend the use of the CONSORT statement in the authors' guidelines for publication
(Table 2). Even considering that most of the journals encourage adherence to the CONSORT statement, the mean average score did not reach the maximum possible score of the evaluation tool. This means that peer-reviewed processes are not detecting incomplete reporting of some of the published articles.

However, there has been a significant trend towards an increase in adherence to CONSORT recommendations in more recent studies: the mean score in the 1999-2004 period was $18.1 \pm$ 4.6, whereas in the 2015 to 2021 period, it rose to $26.7 \pm 3.1$ (approximately $82.2 \%$ of the maximum possible score), with a positive correlation $(r=0.6883$; $\mathrm{p}<0.0001)$. The increase in mean CONSORT scores over time certainly reflects the influence of the reviewers and editors of different journals, who encourage and demand a more complete description of the different stages of the studies. Also, the authors have become acquainted with the CONSORT recommendations and improved their research reporting skills. 
Table 4. Analysis of the scores obtained from CONSORT according to different categories (journals, countries, time period, and follow-up time (ANOVA by posts with Dunn's post-test).

\begin{tabular}{|c|c|c|c|}
\hline \multirow{2}{*}{ Category } & \multirow{2}{*}{ Mean \pm Standard Deviation } & Median & \multirow{2}{*}{$p$-value* } \\
\hline & & (interquartile range) & \\
\hline \multicolumn{4}{|l|}{ Journal } \\
\hline Clinical Oral Investigations & $27.5 \pm 3.4$ & $27.5(23-28)$ & \\
\hline Caries Research & $22.5 \pm 3.9$ & $22.5(19-25.5)$ & \\
\hline Int. Journal of Paediatric Dentistry & $21.5 \pm 3.9$ & $21.5(18.5-24.5)$ & $p=0.218$ \\
\hline Community Dent. Oral Epidemiol. & $18 \pm 5$ & $18(13.5-21)$ & \\
\hline Other* & $24 \pm 5.9$ & $24(17.3-26)$ & \\
\hline \multicolumn{4}{|l|}{ Country } \\
\hline Brazil & $26.8 \pm 3.2^{a}$ & $27(24.3-30)$ & \\
\hline China & $16.4 \pm 4.5^{b}$ & $16(12-20.5)$ & \\
\hline Netherlands & $21.6 \pm 4.5^{a}, b$ & $22(18.3-25)$ & $p<0.001$ \\
\hline Turkey & $19.3 \pm 2.08^{b}$ & $20(17.8-20.8)$ & \\
\hline Other $* *$ & $20.8 \pm 4.5^{c, b}$ & $20.5(18-25)$ & \\
\hline \multicolumn{4}{|l|}{ Publication date } \\
\hline $1999-2004$ & $18.1 \pm 4.6^{b}$ & $17.5(14.5-22)$ & \\
\hline $2005-2009$ & $22.7 \pm 1.5^{a, b}$ & $23(21.5-24)$ & $p<0.001$ \\
\hline $2010-2014$ & $23.0 \pm 4.6^{a, b}$ & $21.5(20-27.0)$ & \\
\hline $2015-2020$ & $26.7 \pm 3.1^{a}$ & $26(25-30)$ & \\
\hline \multicolumn{4}{|l|}{ Follow-up period (year) } \\
\hline 0 to 12 months & $24.3 \pm 4.8$ & $24(23.5-27)$ & \\
\hline 13 to 24 months & $20.0 \pm 6.4$ & $18(16.3-24.8)$ & \\
\hline 25 to 36 months & $21.1 \pm 4.7$ & $20(18.0-22.5)$ & $p=0.274$ \\
\hline 37 to 48 months & $25.3 \pm 2.1$ & $26(23.7-26.7)$ & \\
\hline more than 48 months & $23.5 \pm 2.1$ & $23.5(22-25.0)$ & \\
\hline
\end{tabular}

*Other: 16 journals (BMC Oral Health; Brazilian Dental Science, Pediatric Dentistry, Journal of the Indian Society of Pedodontics and Preventive Dentistry, Journal of Applied Oral Science, Journal of Public Health Dentistry, Contemporary Clinical Dentistry, Journal of Dentistry for Children, Journal of the South African Dental Association, Brazilian Oral Research, Journal the American Dental Association, International Dental Journal, Medical Principles and Practice, Nigerian Journal of Clinical Practice, Journal of Clinical Paediatric Dentistry, Quintessence International, and Journal of Dentistry); **Other: 7 countries (Kenya, Tanzania, South Africa,Australia, Kuwait, India, and Syria).

Knowing that the CONSORT group started their activities in 1996, this finding shows a relatively long period should be allowed before new modalities of research reports are adopted. As with translational research, which requires some time before moving from basic science discoveries into daily practice, the appropriation of the CONSORT recommendations by the subjects involved in the publication process also requires some time before full compliance.

Our study showed that, despite the moderate degree of adherence to CONSORT recommendations, this did not have a strong impact on the quality of papers included in the present study regarding the domains of the Cochrane RoB tool. This can be explained because adherence to the CONSORT statement does not evaluate the quality of RCTs, but it encourages a complete report. We observed there were a large number of papers considered to have an unclear RoB and this is directly linked to a flawed report. If the report is complete, even when some phase of the research is not accomplished correctly, the reader will be able to judge and the unclear scoring would not be applied. This problem probably will be solved with full compliance with the CONSORT statement.

An appropriate randomization process was only achieved by $25 \%$ of the papers, given that it consists of two stages: sequence generation and allocation concealment. Sequence generation is essential so that participants in the test and control groups could 


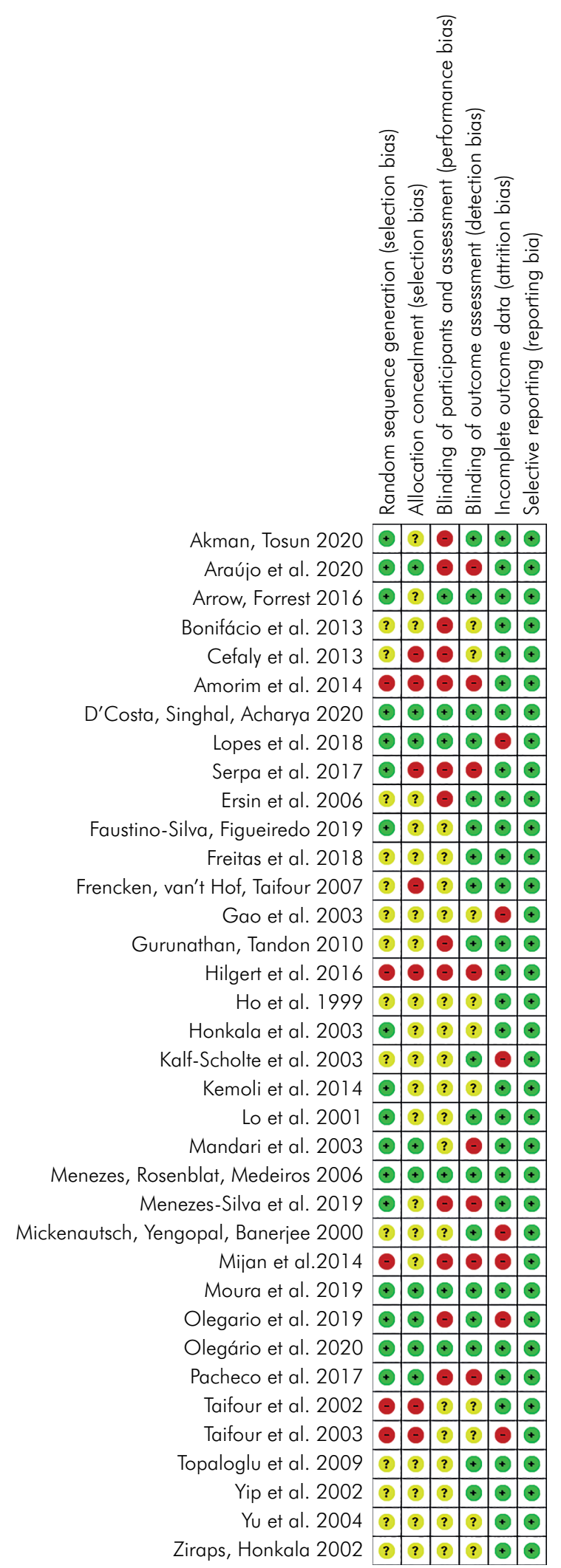

Figure 4. Summary of risk assessment of bias according to the Cochrane tool. have similar characteristics at the beginning of the study and could be exposed to the same chance of receiving the intervention; allocation concealment ensures that neither patients nor operators are aware of the intervention before the study is implemented. ${ }^{70}$ Thus, the insertion of systematic errors or random bias in RCTs may reduce the confidence we have in the study results, as bias may distort the truth towards greater benefit or harm of the intervention. Therefore, we recommend that clinical decision-making should be taken based not on individual RCTs, but on systematic reviews, which are a research design that analyzes the RoB of papers, but also the certainty of the evidence as a whole.

We expected journals with higher impact factors to be more rigorous during the review process, resulting in higher CONSORT scores. However, the impact factor of the journals did not show a significant correlation with the CONSORT scores, nor with the RoB in the included studies. The impact factor reflects the average number of citations of scientific articles published in a given journal. Consequently, the ideal scenario would have been to have those studies with the most complete research reports and better quality papers in the most cited journals. A complete report is fundamental, as it would make the experiment reproducible, a requirement that is inherent to any scientific research, and also would ease up the risk of bias analysis and the confidence in the results.

Among the analyzed CONSORT criteria, protocol registration, study flowchart, and allocation concealment were the least reported items (Figure 3). The registration protocol for clinical trials has been a recommendation from the International Committee of Medical Journals since 2005 $5^{71}$. Protocol registration was reported only by 13 papers (36.1\%). It prevents the selective reporting of outcomes, which distorts the evidence available for decision-making ${ }^{72}$. Every researcher must, before the beginning of the study, register their research protocol in one of the available databases to make it public to all interested parties, including other researchers in the field, reviewers, and editors of scientific journals and even patients that are participating in clinical trials. Examples of digital platforms for registering clinical trials 


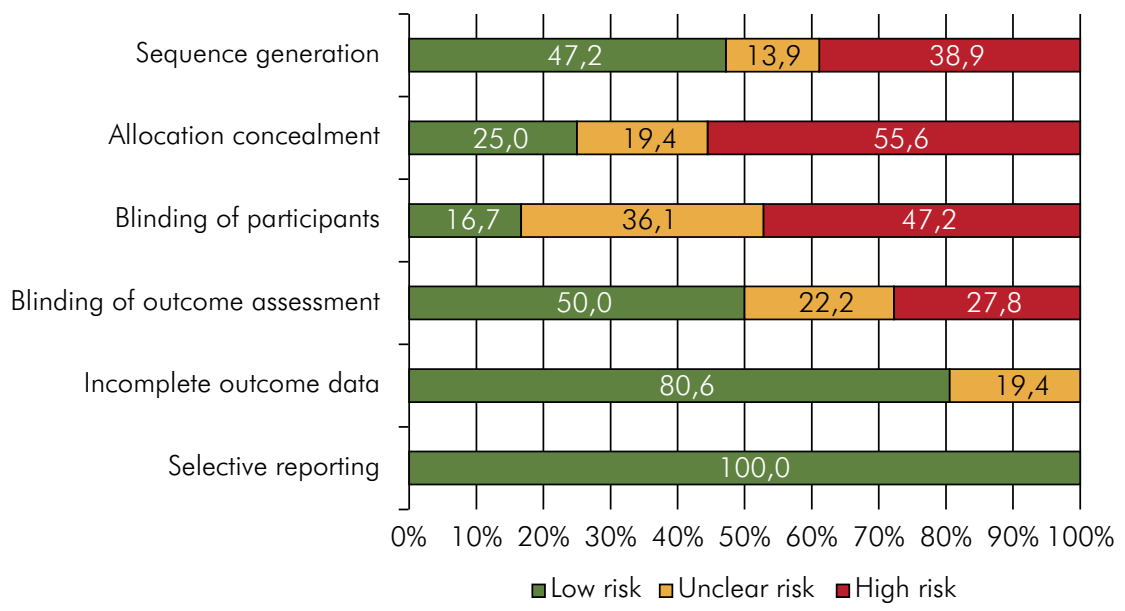

Figure 5. Relative frequencies of studies according to the risk of bias assessment (Cochrane tool).

include ClinicalTrials.gov (https://clinicaltrials. gov/) and EU Clinical Trials Register (https://www. clinicaltrialsregister.eu/).

The lack of a flowchart was detected in approximately $60 \%$ of the studies. The function of the flowchart is to present, quickly and directly, all phases of the clinical trial, including the recruitment of patients, their allocation, and follow-up periods, with the respective patient losses to follow-up. The flowchart allows analyzing the internal and external validity of the trial and it is usually related to better reporting of clinical research. ${ }^{73}$ It is an important criterion that needs to be present in all ART research reports.

Another very important criterion for the quality of the results obtained is the sample size calculation, which was not reported by $50 \%$ of the papers. A recent study reported an even higher percentage (79.1\%) for the period from 1955 to $2013^{74}$, among RCTs taken from systematic reviews in dentistry. A study with a small sample size has limited test power and less chance of detecting a true effect in the comparison between groups, and when they detect a difference, this positive finding may be due to chance alone. Likewise, a very large sample represents unnecessary expenses and an ethical challenge when including excess patients in a clinical trial ${ }^{75}$. This stage is part of the planning and the statistical treatment of the study and numerous factors need to be considered, such as the primary outcome of the study, the type of trial (superiority, non-inferiority, or equivalence), the desired power for the study, among other characteristics. As it has a direct influence on the study result of the clinical trial, this step needs to be carefully described in the study reports.

Our study showed that more than $60 \%$ of the included papers accomplished a follow-up period of 24 months or more. However, one-third of the clinical trials reported a 12-month follow-up (33.3\%), which is probably a very short period to evaluate the longevity of restorations, even for deciduous teeth. Therefore, we certainly encourage the authors to plan longer follow-up periods in future research studies, particularly if permanent teeth are included.

Most studies were published in the 1999-2004 and 2015-2021 periods. The first period coincides with the years following the dissemination of the ART technique to the world dental community and the endorsement by the World Health Organization in $1994 .{ }^{76}$ In recent years, an increased number of publications have been justified by the recognized effectiveness of the selective removal of decayed tissue techniques and the growth of minimal intervention dentistry, ${ }^{77}$ which has the ART protocol as one of its most common procedures.

There are some limitations to the present study. Despite a very comprehensive search in different databases with specific vocabulary and keywords, we may have missed some articles. For instance, no Japanese, Chinese, or Korean database was searched. Also, we did not identify papers that fulfilled the eligibility criteria in languages other than English. 
A large number of publications about ART are by Brazilian authors; they also showed the highest mean CONSORT scores, which reflects the methodological evolution of Brazilian dental research and the acceptance ART has gained in Brazilian dentistry, particularly in pediatric dentistry. ART is part of the national oral health program in Brazil, with the inclusion of the technique in the curricula of Brazilian dental schools. This is probably connected to the fact that untreated dental caries is the main component in the dmf-t index (2.43) in 5-year-old children in Brazil, affecting mainly the low-income population and their access to healthcare services, ${ }^{78}$ and ART is a protocol with the potential to expand service and dental assistance coverage for this population, ${ }^{79}$ and it is also a key component of WHO's Basic Package of Oral Care (BPOC) for making restorative dental treatment more reachable to communities in developing nations. ${ }^{66}$

It is encouraging to note that adherence to CONSORT recommendations has increased over time. Notwithstanding, this does not mean that ART research in pediatric dentistry is free of bias and thoroughly reported. By providing quantitative data about ART research, we hope to encourage a deeper analysis that may lead authors to refine their methodology and research reports and improve the peer-review process. Thus, future RCTs should be targeted on non-inferiority designs with a high test power and low random error to corroborate the advantages of adopting the ART approach over "conventional restorative techniques".

\section{Conclusion}

Regarding RCTs on the longevity of ART restorations, it may be concluded that adherence to the CONSORT statement was not fully achieved, despite the inclusion of CONSORT guidelines in the publication guidelines of different journals. Also, most of the included papers have unclear and high RoB. These findings indicate that adherence to the CONSORT recommendations should be encouraged, which may indirectly refine the research methodology and reporting and improve RoB in RCTs.

\section{References}

1. Frencken JE. Atraumatic restorative treatment and minimal intervention dentistry. Br Dent J. 2017 Aug;223(3):183-9. https://doi.org/10.1038/sj.bdj.2017.664

2. Garrocho-Rangel A, Ruiz-Rodríguez S, Gaitán-Fonseca C, Pozos-Guillén A. Randomized Clinical Trials in Pediatric Dentistry: Application of Evidence-Based Dentistry through the CONSORT Statement. J Clin Pediatr Dent. 2019;43(4):219-30. https://doi.org/10.17796/1053-4625-43.4.1

3. Chiappelli F. Evidence-Based Dentistry: Two Decades and Beyond. J Evid Based Dent Pract. 2019 Mar;19(1):7-16. https://doi.org/10.1016/i.jebdp.2018.05.001

4. Ruengrungsom C, Palamara JE, Burrow MF. Comparison of ART and conventional techniques on clinical performance of glass-ionomer cement restorations in load bearing areas of permanent and primary dentitions: A systematic review. J Dent. 2018 Nov;78:1-21. https://doi.org/10.1016/i.jdent.2018.07.008

5. de Amorim RG, Frencken JE, Raggio DP, Chen X, Hu X, Leal SC. Survival percentages of atraumatic restorative treatment (ART) restorations and sealants in posterior teeth: an updated systematic review and meta-analysis. Clin Oral Investig. 2018 Nov;22(8):2703-25. https://doi.org/10.1007/s00784-018-2625-5

6. Raggio DP, Hesse D, Lenzi TL, Guglielmi CA, Braga MM. Is Atraumatic restorative treatment an option for restoring occlusoproximal caries lesions in primary teeth? A systematic review and meta-analysis. Int J Paediatr Dent. 2013 Nov;23(6):435-43. https://doi.org/10.1111/ipd.12013

7. Dorri M, Martinez-Zapata MJ, Walsh T, Marinho VC, Sheiham Deceased A, Zaror C. Atraumatic restorative treatment versus conventional restorative treatment for managing dental caries. Cochrane Database Syst Rev. 2017 Dec;12(12):CD008072. https://doi.org/10.1002/14651858.CD008072.pub2

8. Mickenautsch S, Yengopal V, Banerjee A. Atraumatic restorative treatment versus amalgam restoration longevity: a systematic review. Clin Oral Investig. 2010 Jun;14(3):233-40. https://doi.org/10.1007/s00784-009-0335-8

9. Göstemeyer G, Levey C. The Problem: Relevance, Quality, and Homogeneity of Trial Designs, Outcomes, and Reporting. Monogr Oral Sci. 2018;27:146-54. https://doi.org/10.1159/000487841 
10. Begg C, Cho M, Eastwood S, Horton R, Moher D, Olkin I, et al. Improving the quality of reporting of randomized controlled trials. The CONSORT statement. JAMA. 1996 Aug;276(8):637-9. https://doi.org/10.1001/jama.1996.03540080059030

11. Sarkis-Onofre R, Cenci MS, Demarco FF, Lynch CD, Fleming PS, Pereira-Cenci T, et al. Use of guidelines to improve the quality and transparency of reporting oral health research. J Dent. 2015 Apr;43(4):397-404. https://doi.org/10.1016/i.jdent.2015.01.006

12. Sarkis-Onofre R, Marchini L, Spazzin AO, Santos MB. Randomized Controlled Trials in Implant Dentistry: Assessment of the Last 20 Years of Contribution and Research Network Analysis. J Oral Implantol. 2019 Aug;45(4):327-33. https://doi.org/10.1563/aaid-joi-D-18-00276

13. Sarkis-Onofre R, Cenci MS, Moher D, Pereira-Cenci T. Research Reporting Guidelines in Dentistry: A Survey of Editors. Braz Dent J. 2017 Jan-Feb;28(1):3-8. https://doi.org/10.1590/0103-6440201601426

14. Loguercio AD, Maran BM, Hanzen TA, Paula AM, Perdigão J, Reis A. Randomized clinical trials of dental bleaching - Compliance with the CONSORT Statement: a systematic review. Braz Oral Res. 2017 Aug;31 suppl 1:e60. https://doi.org/10.1590/1807-3107bor-2017.vol31.0060

15. Reis A, Geus JL, Wambier L, Schroeder M, Loguercio AD. Compliance of randomized clinical trials in noncarious cervical lesions with the Consort Statement: a systematic review of methodology. Oper Dent. 2018 May/Jun;43(3):E129-51. https://doi.org/10.2341/17-060-L

16. Lucena C, Souza EM, Voinea GC, Pulgar R, Valderrama MJ, De-Deus G. A quality assessment of randomized controlled trial reports in endodontics. Int Endod J. 2017 Mar;50(3):237-50. https://doi.org/10.1111/iej.12626

17. Flint HE, Harrison JE. How well do reports of clinical trials in the orthodontic literature comply with the CONSORT statement? J Orthod. 2010 Dec;37(4):250-61. https://doi.org/10.1179/14653121043191

18. Savithra P, Nagesh LS. Have CONSORT guidelines improved the quality of reporting of randomised controlled trials published in public health dentistry journals? Oral Health Prev Dent. 2013;11(2):95-103. https://doi.org/10.3290/i.ohpd.a29359

19. loannidis JP. Meta-research: why research on research matters. PLoS Biol. 2018 Mar;16(3):e2005468. https://doi.org/10.1371/journal.pbio.2005468

20. loannidis JP, Fanelli D, Dunne DD, Goodman SNJPB. Meta-research: evaluation and improvement of research methods and practices. 2015; 13(10): e1002264. https://doi.org/10.1371/journal.pbio.1002264.

21. Page MJ, Moher D, Bossuyt PM, Boutron I, Hoffmann TC, Mulrow CD, et al. PRISMA 2020 explanation and elaboration: updated guidance and exemplars for reporting systematic reviews. BMJ. 2021 Mar;372(160):nl60. https://doi.org/10.1136/bmj.nl60

22. Moher D, Hopewell S, Schulz KF, Montori V, Gøtzsche PC, Devereaux PJ, et al.; Consolidated Standards of Reporting Trials Group. CONSORT 2010 Explanation and Elaboration: updated guidelines for reporting parallel group randomised trials. J Clin Epidemiol. 2010 Aug;63(8):el-37. https://doi.org/10.1016/i.jclinepi.2010.03.004

23. Higgins JP, Altman DG, Gøtzsche PC, Jüni P, Moher D, Oxman AD, et al.; Cochrane Bias Methods Group; Cochrane Statistical Methods Group. The Cochrane Collaboration's tool for assessing risk of bias in randomised trials. BMJ. 2011 Oct;343 oct18 2:d5928. https://doi.org/10.1136/bmi.d5928

24. Hesse D, Araujo MP, Olegário IC, Innes N, Raggio DP, Bonifácio CC. Atraumatic restorative treatment compared to the hall technique for occluso-proximal cavities in primary molars: study protocol for a randomized controlled trial. Trials. 2016 Mar;17(1):169. https://doi.org/10.1186/s13063-016-1270-z

25. Olegário IC, Hesse D, Bönecker M, Imparato JC, Braga MM, Mendes FM, et al. Effectiveness of conventional treatment using bulk-fill composite resin versus Atraumatic Restorative Treatments in primary and permanent dentition: a pragmatic randomized clinical trial. BMC Oral Health. 2016 Aug;17(1):34. https://doi.org/10.1186/s12903-016-0260-6

26. Ladewig NM, Sahiara CS, Yoshioka L, Olegário IC, Floriano I, Tedesco TK, et al. Efficacy of conventional treatment with composite resin and atraumatic restorative treatment in posterior primary teeth: study protocol for a randomised controlled trial. BMJ Open. 2017 Jul;7(7):e015542. https://doi.org/10.1136/bmiopen-2016-015542

27. Frencken JE, van 't Hof MA, Taifour D. Caries preventive effect of occlusal sealant extension to ART restorations compared with non-extended amalgam restorations. Oral Health Prev Dent. 2007;5(1):55-61.

28. Hesse D, Bonifácio CC, Guglielmi Cde A, Franca C, Mendes FM, Raggio DP. Low-cost glass ionomer cement as ART sealant in permanent molars: a randomized clinical trial. Braz Oral Res. 2015; 29. https://doi.org/10.1590/1807-3107BOR-2015.vol29.0063

29. Zhang W, Chen X, Fan MW, Mulder J, Huysmans MC, Frencken JE. Do light cured ART conventional high-viscosity glass-ionomer sealants perform better than resin-composite sealants: a 4-year randomized clinical trial. Dent Mater. 2014 May;30(5):487-92. https://doi.org/10.1016/i.dental.2014.01.016

30. Hesse D, Guglielmi CA, Raggio DP, Bönecker MJ, Mendes FM, Bonifácio CC. Atraumatic Restorative Treatment-Sealed versus Nonsealed First Permanent Molars: A 3-Year Split-Mouth Clinical Trial. Caries Res. 2021;55(1):12-20. https://doi.org/10.1159/000506466

31. Caro TE, Aguilar AA, Saavedra JH, AlfayaTA, França CM, Fernandes KPS, et al. Comparison of operative time, costs and self-reported pain in children treated with atraumatic restorative treatment and conventional restorative treatment. J Med Sci Tech. 2012;53(4):159-63.

32. Arrow $P$, Forrest $\mathrm{H}$. Atraumatic restorative treatments improve child oral health-related quality of life: a noninferiority randomized controlled trial. Community Dent Oral Epidemiol. 2020 Aug;48(4):349-56. https://doi.org/10.1111/cdoe.12539 
33. Berg J. When primary molar lesions are cavitated into dentin, glass ionomer has similar 2-year survival to resin composite as a restorative material when using the "ART" technique. J Evid Based Dent Pract. 2008 Mar;8(1):24-5. https://doi.org/10.1016/i.jebdp.2007.12.007

34. Molina GF, Ulloque MJ, Mazzola I, Mulder J, Frencken J. Randomized controlled trial of class II ART high-viscosity glass-ionomer cement and conventional resin-composite restorations in permanent dentition: two-year survival. J Adhes Dent. 2020;22(6):555-65. https://doi.org/10.3290/i.jad.a45512

35. Shivanna MM, Ganesh S, Khanagar SB, Naik S, Divakar DD, Al-Kheraif AA, et al. Twelve-month evaluation of the atraumatic restorative treatment approach for class III restorations: an interventional study. World J Clin Cases. 2020 Sep;8(18):3999-4009. https://doi.org/10.12998/wicc.v8.i18.3999

36. Jiang M, Wong MC, Chu CH, Dai L, Lo EC. A 24 -month randomized controlled trial on the success rates of restoring untreated and SDF-treated dentine caries lesions in primary teeth with the ART approach. J Dent. 2020 Sep;100:103435. https://doi.org/10.1016/i.jdent.2020.103435

37. Arrow $\mathrm{P}$, Forrest $\mathrm{H}$. Atraumatic restorative treatments reduce the need for dental general anaesthesia: a non-inferiority randomized, controlled trial. Aust Dent J. 2020 Jun;65(2):158-67. https://doi.org/10.1111/adj.12749

38. Lopes CMF, Schubert EW, Martins AS, Loguercio AD, Reis A, Chibinski AC, et al. Randomized clinical trial of ART Class II restorations using two glass ionomer cements: one-year follow-up. Pediatr Dent. 2018 Mar;40(2):98-104

39. Menezes JP, Rosenblatt A, Medeiros E. Clinical evaluation of atraumatic restorations in primary molars: a comparison between 2 glass ionomer cements. J Dent Child (Chic). 2006 May-Aug;73(2):91-7.

40. Moura MS, Sousa GP, Brito MH, Silva MC, Lima MD, Moura LF, et al. Does low-cost GIC have the same survival rate as high-viscosity GIC in atraumatic restorative treatments? A RCT. Braz Oral Res. 2020 Jan;33:e125. https://doi.org/10.1590/1807-3107bor-2019.vol33.0125

41. Olegário IC, Ladewig NM, Hesse D, Bonifácio CC, Braga MM, Imparato JC, et al. Is it worth using low-cost glass ionomer cements for occlusal ART restorations in primary molars? 2-year survival and cost analysis of a Randomized clinical trial. J Dent. 2020 Oct;101:103446. https://doi.org/10.1016/i.jdent.2020.103446

42. Arrow P. Restorative outcomes of a minimally invasive restorative approach based on atraumatic restorative treatment to manage early childhood caries: a randomised controlled trial. Caries Res. 2016;50(1):1-8. https://doi.org/10.1159/000442093

43. Faustino-Silva DD, Figueiredo MC. Atraumatic restorative treatment-ART in early childhood caries in babies: 4 years of randomized clinical trial. Clin Oral Investig. 2019 Oct;23(10):3721-9. https://doi.org/10.1007/s00784-019-02800-8

44. Freitas MC, Fagundes TC, Modena KC, Cardia GS, Navarro MF. Randomized clinical trial of encapsulated and hand-mixed glass-ionomer ART restorations: one-year follow-up. J Appl Oral Sci. 2018 Jan;26(0):e20170129. https://doi.org/10.1590/1678-7757-2017-0129

45. Ho TF, Smales RJ, Fang DT. A 2-year clinical study of two glass ionomer cements used in the atraumatic restorative treatment (ART) technique. Community Dent Oral Epidemiol. 1999 Jun;27(3):195-201. https://doi.org/10.1111/j.1600-0528.1999.tb02010.x

46. Honkala E, Behbehani J, Ibricevic H, Kerosuo E, Al-Jame G. The atraumatic restorative treatment (ART) approach to restoring primary teeth in a standard dental clinic. Int J Paediatr Dent. 2003 May;13(3):172-9. https://doi.org/10.1046/i.1365-263X.2003.00455.x

47. Kemoli AM, Opinya GN, van Amerongen WE, Mwalili SM. Two-year survival rates of proximal atraumatic restorative treatment restorations in relation to glass ionomer cements and Postrestoration meals consumed. Pediatr Dent. 2011 May-Jun;33(3):246-51.

48. Lo EC, Luo Y, Fan MW, Wei SH. Clinical investigation of two glass-ionomer restoratives used with the atraumatic restorative treatment approach in China: two-years results. Caries Res. 2001 Nov-Dec;35(6):458-63. https://doi.org/10.1159/000047490

49. Topaloglu-Ak A, Eden E, Frencken JE, Oncag O. Two years survival rate of class II composite resin restorations prepared by ART with and without a chemomechanical caries removal gel in primary molars. Clin Oral Investig. 2009 Sep;13(3):325-32. https://doi.org/10.1007/s00784-008-0241-5

50. Yip HK, Smales RJ, Yu C, Gao XJ, Deng DM. Comparison of atraumatic restorative treatment and conventional cavity preparations for glass-ionomer restorations in primary molars: one-year results. Quintessence Int. 2002 Jan;33(1):17-21.

51. Yu C, Gao XJ, Deng DM, Yip HK, Smales RJ. Survival of glass ionomer restorations placed in primary molars using atraumatic restorative treatment (ART) and conventional cavity preparations: 2-year results. Int Dent J. 2004 Feb;54(1):42-6. https://doi.org/10.1111/j.1875-595X.2004.tb00251.x

52. Ziraps A, Honkala E. Clinical trial of a new glass ionomer for an atraumatic restorative treatment technique in class I restorations placed in Latvian school children. Med Princ Pract. 2002;11 Suppl 1:44-7. https://doi.org/10.1159/000057778

53. Akman H, Tosun G. Clinical evaluation of bulk-fill resins and glass ionomer restorative materials: A 1-year follow-up randomized clinical trial in children. Niger J Clin Pract. 2020 Apr;23(4):489-97. https://doi.org/10.4103/njcp.njcp_519_19

54. Araujo MP, Innes NP, Bonifácio CC, Hesse D, Olegário IC, Mendes FM, et al. Atraumatic restorative treatment compared to the Hall Technique for occluso-proximal carious lesions in primary molars; 36-month follow-up of a randomised control trial in a school setting. BMC Oral Health. 2020 Nov;20(1):318. https://doi.org/10.1186/s12903-020-01298-x 
- Título resumido título resumido título resumido título resumido título resumido título resumido título resumido título resumido

55. Bonifácio CC, Hesse D, Raggio DP, Bönecker M, van Loveren C, van Amerongen WE. The effect of GIC-brand on the survival rate of proximal-ART restorations. Int J Paediatr Dent. 2013 Jul;23(4):251-8. https://doi.org/10.1111/j.1365-263X.2012.01259.x

56. Cefaly D. Barata TJE, Bresciani E, Fagundes TC, Navarro MFL. Clinical evaluation of multiple-surface ART restorations: three-year follow-up. Braz Dent Sci. 2013;74(3):203-8. https://doi.org/10.14295/bds.2013.v16i1.872

57. Amorim RG, Leal SC, Mulder J, Creugers NH, Frencken JE. Amalgam and ART restorations in children: a controlled clinical trial. Clin Oral Investig. 2014 Jan;18(1):117-24. https://doi.org/10.1007/s00784-013-0955-x

58. Serpa EBM, Clementino MA, Granville-Garcia AF, Rosenblatt A. The effect of atraumatic restorative treatment on adhesive restorations for dental caries in deciduous molars. J Indian Soc Pedod Prev Dent. 2017 Apr-Jun;35(2):167-73. https://doi.org/10.4103/JISPPD.JISPPD_98_16

59. Ersin NK, Candan U, Aykut A, Onçağ O, Eronat C, Kose T. A clinical evaluation of resin-based composite and glass ionomer cement restorations placed in primary teeth using the ART approach: results at 24 months. J Am Dent Assoc. 2006 Nov;137(11):1529-36. https://doi.org/10.14219/jada.archive.2006.0087

60. Frencken JE, Taifour D, Hof MA. Survival of ART and amalgam restorations in permanent teeth of children after 6.3 years. J Dent Res. 2006 Jul;85(7):622-6. https://doi.org/10.1177/154405910608500708

61. Gao W, Peng D, Smales RJ, Yip KH. Comparison of atraumatic restorative treatment and conventional restorative procedures in a hospital clinic: evaluation after 30 months. Quintessence Int. 2003 Jan;34(1):31-7.

62. Mickenautsch S, Kopsala J, Rudolph MJ, Ogunbodede EO. Clinical evaluation of the ART approach and materials in peri-urban farm schools of the Johannesburg area. SADJ. 2000 Jul;55(7):364-8.

63. Mijan M, Amorim RG, Leal SC, Mulder J, Oliveira L, Creugers NH, et al. The 3.5-year survival rates of primary molars treated according to three treatment protocols: a controlled clinical trial. Clin Oral Investig. 2014 May;18(4):1061-9. https://doi.org/10.1007/s00784-013-1077-1

64. Taifour D, Frencken JE, Beiruti N, Hof MA, Truin GJ, van Palenstein Helderman WH. Comparison between restorations in the permanent dentition produced by hand and rotary instrumentation: survival after 3 years. Community Dent Oral Epidemiol. 2003 Apr;31(2):122-8. https://doi.org/10.1034/j.1600-0528.2003.00027.x

65. Taifour D, Frencken JE, Beiruti N, van '† Hof MA, Truin GJ. Effectiveness of glass-ionomer (ART) and amalgam restorations in the deciduous dentition: results after 3 years. Caries Res. 2002 Nov-Dec;36(6):437-44. https://doi.org/10.1159/000066531

66. D'Costa VG, Singhal DK, Acharya S. Efficacy of GC Gold Label 9 and GC Miracle Mix ${ }^{\circledR}$ Restorations using Atraumatic Restorative Treatment (ART) in rural settings: a randomized controlled trial. J Clin Pediatr Dent. 2020;44(3):148-53. https://doi.org/10.17796/1053-4625-44.3.3

67. Pacheco ALB. Olegário IC, Bonifácio CC, Calvo AFB, Imparato JCP, Raggio DP. One year survival rate of ketac molar versus vitro molar for occlusoproximal ART restorations: a RCT. Braz Oral Res. 2017 Nov;31(0):e88. https://doi.org/10.1590/1807-3107bor-2017.vol31.0088.

68. Fleming PS, Lynch CD, Pandis N. Randomized controlled trials in dentistry: common pitfalls and how to avoid them. J Dent. 2014 Aug;42(8):908-14. https://doi.org/10.1016/i.jdent.2014.06.004

69. Cioffi I, Farella M. Quality of randomised controlled trials in dentistry. Int Dent J. 2011 Feb;61(1):37-42. https://doi.org/10.1111/j.1875-595X.2011.00007.x

70. De Carvalho A, Silva V, Grande A. Avaliação do risco de viés de ensaios clínicos randomizados pela ferramenta da colaboração Cochrane. J Diagn Tratamento. 2013;18(1):38-44.

71. Khalil O, Govindarajan R, Safar M, Hutchins L, Mehta P. Clinical trial registration and the ICMJE. JAMA. 2005 Jan;293(2):157. https://doi.org/10.1001/jama.293.2.157-b

72. DeAngelis CD, Drazen JM, Frizelle FA, Haug C, Hoey J, Horton R, et al. Clinical trial registration: a statement from the International Committee of Medical Journal Editors. Arch Otolaryngol Head Neck Surg. 2005 Jun;131 (6):479-80. https://doi.org/10.1001/archotol.131.6.479

73. Egger M, Jüni P, Bartlett C. Value of flow diagrams in reports of randomized controlled trials. JAMA. 2001 Apr;285(15):1996-9. https://doi.org/10.1001/jama.285.15.1996

74. Saltaji H, Armijo-Olivo S, Cummings GG, Amin M, Flores-Mir C. Randomized clinical trials in dentistry: risks of bias, risks of random errors, reporting quality, and methodologic quality over the years 1955-2013. PLoS One. 2017 Dec;12(12):e0190089. https://doi.org/10.1371/journal.pone.0190089

75. Ebrahim Valojerdi A, Tanha K, Janani L. Important considerations in calculating and reporting of sample size in randomized controlled trials. Med J Islam Repub Iran. 2017 Dec;31(1):127. https://doi.org/10.14196/mjiri.31.127

76. Frencken JE, Pilot T, Songpaisan Y, Phantumvanit P. Atraumatic restorative treatment (ART): rationale, technique, and development. J Public Health Dent. 1996; 56(3 Spec No): 135-40; discussion 61-3. https://doi.org/10.1111/j.17527325.1996.tb02423.x.

77. Banerjee A, Frencken JE, Schwendicke F, Innes NP. Contemporary operative caries management: consensus recommendations on minimally invasive caries removal. Br Dent J. 2017 Aug;223(3):215-22. https://doi.org/10.1038/sj.bdj.2017.672 
78. Umeda JE, Chichakly K, Passos GF, Terada RSS, Pascotto RC, Fujimaki M. System dynamics modeling for tooth decay treatment in Brazilian children. Braz Oral Res. 2020;34:e017. https://doi.org/10.1590/1807-3107bor-2020.vol34.0017

79. Frencken JE, Leal SC, Navarro MF. Twenty-five-year atraumatic restorative treatment (ART) approach: a comprehensive overview. Clin Oral Investig. 2012 Oct;16(5):1337-46. https://doi.org/10.1007/s00784-012-0783-4

80. Deepa G, Shobha T. A clinical evaluation of two glass ionomer cements in primary molars using atraumatic restorative treatment technique in India: 1 year follow up. Int J Paediatr Dent. 2010 Nov;20(6):410-8. doi: 10.1111/j.1365-263X.2010.01067.x

81. Hilgert LA, Frencken JE, de Amorim RG, Mulder J, Leal SC. A study on the survival of primary molars with intact and with defective restorations. Int J Paediatr Dent. 2016 Sep;26(5):383-90. doi: 10.1111/ipd.12215

82. Kalf-Scholte SM, van Amerongen WE, Smith AJ, van Haastrecht HJ. Atraumatic restorative treatment (ART): a three-year clinical study in Malawi--comparison of conventional amalgam and ART restorations. J Public Health Dent. 2003 Spring;63(2):99-103. doi: 10.1111/j.1752-7325.2003.tb03482.x

83. Mandari GJ, Truin GJ, van't Hof MA, Frencken JE. Effectiveness of three minimal intervention approaches for managing dental caries: survival of restorations after 2 years. Caries Res. 2001 Mar-Apr;35(2):90-4. doi: 10.1159/000047438

84. Menezes-Silva R, Velasco SRM, Bastos RS, Molina G, Honório HM, Frencken JE, Navarro MFL. Randomized clinical trial of class II restoration in permanent teeth comparing ART with composite resin after 12 months. Clin Oral Investig. 2019 Sep;23(9):3623-3635. doi: 10.1007/s00784-018-2787-1

85. Olegário IC, Hesse D, Mendes FM, Bonifácio CC, Raggio DP. Glass carbomer and compomer for ART restorations: 3-year results of a randomized clinical trial. Clin Oral Investig. 2019 Apr;23(4):1761-1770. doi: 10.1007/s00784-018-2593-9 